2015

\title{
The Misguided Search for the Nature of Law
}

Dan Priel

Osgoode Hall Law School of York University, dpriel@osgoode.yorku.ca

Follow this and additional works at: http:// digitalcommons.osgoode.yorku.ca/olsrps

Part of the Law Commons

\section{Recommended Citation}

Priel, Dan, "The Misguided Search for the Nature of Law" (2015). Osgoode Legal Studies Research Paper Series. 110.

http://digitalcommons.osgoode.yorku.ca/olsrps/110

This Article is brought to you for free and open access by the Research Papers, Working Papers, Conference Papers at Osgoode Digital Commons. It has been accepted for inclusion in Osgoode Legal Studies Research Paper Series by an authorized administrator of Osgoode Digital Commons. 
Osgoode Legal Studies Research Paper No. 34

Vol. 11/ Issue. 07/ (2015)

\title{
The Misguided Search for the Nature of Law
}

\author{
Dan Priel
}

\begin{abstract}
:
Within analytic jurisprudence the question "what is law?" is often taken to be of primary significance for two distinct reasons. First, it is thought to assume logical priority to normative questions: before one can say something about law, one needs to know what law is. Second, this inquiry is also thought to be uniquely philosophical, a non-empirical, presociological investigation that can then tell empirical investigators what they need to look for if they want to find instances of law in the world. This article offers a general critique of this view. I start with examining several arguments claiming that jurisprudence is not conceptual, since if these arguments are true, they imply that critiques of conceptual jurisprudence are misguided. I argue that such arguments involve a terminological change more than a challenge or a substantive alternative to conceptual jurisprudence. I then turn to examining conceptual jurisprudence itself. I distinguish between two families of views on concepts, "externalism," which conceives of concepts as abstract entities, and "internalism," which conceives of concepts as basic units of thought. Because of this difference, these two views lead to two quite different characterizations of conceptual jurisprudence, each calling for different response. Nevertheless, I argue that both are unsuccessful. I offer a series of arguments against each view: the main argument against the externalist position is that it is viciously circular (as it necessarily assumes the view of law it defends); the main argument against the internalist view is a bad form of sociology. I conclude with brief hints as to what a nonconceptual jurisprudence would look like.
\end{abstract}

\section{Keywords:}

Conceptual jurisprudence, nature of law, conceptual analysis, H.L.A. Hart.

Author(s):

Dan Priel

Associate Professor

Osgoode Hall Law School

E: dpriel@osgoode.yorku.ca 


\title{
The Misguided Search for the Nature of Law
}

\author{
Dan Priel
}

\begin{abstract}
Within analytic jurisprudence the question "what is law?" is often taken to be of primary significance for two distinct reasons. First, it is thought to assume logical priority to normative questions: before one can say something about law, one needs to know what law is. Second, this inquiry is also thought to be uniquely philosophical, a non-empirical, pre-sociological investigation that can then tell empirical investigators what they need to look for if they want to find instances of law in the world. This article offers a general critique of this view. I start with examining several arguments that jurisprudence is not conceptual, since if true, they render any critique of jurisprudence as conceptual as misguided. I argue that such arguments involve a terminological change more than a substantive alternative to conceptual jurisprudence. I then turn to examining conceptual jurisprudence itself. I distinguish between two families of views on concepts, "externalism," which conceives of concepts as abstract entities, and "internalism," which conceives of concepts as basic units of thought. Because of this difference, these two views lead to two quite different characterizations of conceptual jurisprudence, each calling for different kinds of arguments. I offer a series of arguments against each view: the main argument against the externalist position is that it is viciously circular (as it necessarily assumes the view of law it defends); the main argument against the internalist view is a bad form of sociology. I conclude with brief hints as to what a non-conceptual jurisprudence would look like.
\end{abstract}

\section{Introduction}

The question I want to examine in this article looks deceptively simple: What is the object of jurisprudence? What is it about? For many legal philosophers the answer to this question is obvious: Jurisprudence is about law in general. This is taken to mean that jurisprudence is, first and foremost, a value-neutral description of the nature of law. ${ }^{1}$ What I hope to show is that this

" Associate Professor, Osgoode Hall Law School. Thanks to participants at a workshop in Edinburgh University, and especially to Luíz Duarte d'Alameida (the commentator on the paper), Eliot Michaelson, and Lucas Miotto, for their comments on an earlier version of this paper. Though the overall conclusion remained largely unchanged, their comments have led to many changes in the essay. This is a corrected version of the earlier version uploaded to SSRN. Errors may still remain. Comments to dpriel@osgoode.yorku.ca are welcome.

This essay is dedicated to the memory of an earlier version of this essay that, together with four other more-orless finished but unbacked-up papers, were lost when a laptop of mine was stolen. Those who remain doubtful about the argument in this paper are encouraged to try and find the lost computer and in it the essay where all their questions and objections were anticipated and definitively answered.

${ }^{1}$ See, among many others, H.L.A. HART, ThE CONCEPT OF LAW, at vi, 239-44 (3d ed. 20I2); ANDREI Marmor, Philosophy of LaW i35 (20ir); Michael S. Moore, Educating Oneself in Public: CRitical 
seemingly obvious answer hides more than it reveals. Presented slightly differently, my target is what is sometimes called "conceptual jurisprudence," an inquiry about law that purports to explicate, elucidate, or describe the "concept," the "essence," or the "nature" of law. ${ }^{2}$ In this essay I am trying to get a clearer sense of what is the thing being explicated, elucidated, or described. I consider various ways of answering this question. My conclusion is wholly negative: I hope to show that conceptual jurisprudence is a hopeless enterprise. If this is true, this requires some fundamental rethinking of what is still perceived as a fundamental aim of philosophical reflection about law.

To many defenders of this enterprise, the search for the nature or concept of law calls for clarifying and defending "conceptual analysis," a traditional philosophical practice aimed at identifying the true nature of things. Much of the work on the aims of jurisprudence thus focused on the viability of conceptual analysis in general. Among those, Brian Leiter has probably been the most persistent critic of conceptual jurisprudence. He did so mainly by relying on general criticisms of conceptual analysis, which he then applied to the domain of jurisprudence. At times he drew on W.V.O. Quine's work against the analytic/synthetic distinction. Quine's argument, in a nutshell, was that conceptual analysis seeks to discover analytic truths, i.e. truth in virtue of the meaning of terms alone, but that there are no such truths. ${ }^{3}$ If this is true, then there is no such thing as conceptual analysis, of law as much as of anything else. A second line of argument in Leiter's criticism of conceptual jurisprudence, again following more general critiques of conceptual analysis, has been to argue that philosophers' failure to provide an adequate analysis of even one concept strongly suggest (even if they do not prove) that the entire enterprise should be abandoned. ${ }^{4}$

While I agree with Leiter that defenders of conceptual jurisprudence have done little (even in response to Leiter's work) to acknowledge, let alone address, the many works challenging

Essays In JuRISPRUdence 88 (2000); Jules L. Coleman, Beyond the Separability Thesis: Moral Semantics and the Methodology of Jurisprudence, 27 OXFORD J. LEGAL STUD. 58I, 597-608 (2007).

${ }^{2}$ Another central feature of this descriptivist view is that this description is morally neutral. See, e.g., HART, supra note I, at 239; MARMOR, supra note I, at I35. I criticized this view elsewhere. See Danny Priel, Evaluating Descriptive Jurisprudence, 52 AM. J. JURIS. I39 (2007). In this essay I largely set the question of the possibility of morally-neutral jurisprudence to focus on the question of the object of conceptual jurisprudence.

${ }^{3}$ See W.V. Quine, Two Dogmas of Empiricism, 6o PHIL. REV. 20 (1951).

${ }^{4}$ See Brian Leiter, The Demarcation Problem in Jurisprudence: A New Case for Skepticism, in NEUTRALITY AND TheOrY OF LAW I6I, I67 (Jordi Ferrer Beltrán et al. eds., 2013) [hereinafter NEUTRALITY]. Green suggested that despite his avowed rejection of conceptual analysis, Leiter in fact makes conceptual claims about law in the very same essay. See Leslie Green, The Morality in Law, in READING HLA HART's THE CONCEPT OF LAW I77, 200-02 (Luíz Duarte d'Almeida et al. eds., 20I3). While I leave it for Leiter to answer this particular charge, I address a version of this argument in Section IV.B, infra. 
conceptual analysis in general philosophical literature, ${ }^{5} \mathrm{I}$ think Leiter's strategy is inadequate for two reasons. First, in some of his writings Leiter suggests that outside legal philosophy there is universal agreement that conceptual analysis is dead. He writes, for example, "post-Quine, we know (don't we?) that the analytic-synthetic distinction does not mark an epistemic difference but a socio-historical one." ${ }^{6}$ No doubt, if conceptual analysis in general is indefensible, the same must be true of any special case of it. But the philosophical terrain is not as clear as Leiter presents it, and Quine's arguments are not universally accepted. ${ }^{7}$ The second, and to my mine more important, shortcoming of Leiter's approach, is its inattention to the details of conceptual jurisprudence. Different writers mean different, sometimes inconsistent, things when they refer to "conceptual jurisprudence," when they say they seek to identify "the concept/essence/nature of law," or when they say they are answering the question "what is law?" Until these different senses are disentangled, a defender of conceptual jurisprudence may reply that what she means by conceptual jurisprudence is not affected by Quine's (and by implication, Leiter's) critique. ${ }^{8}$ My approach therefore takes on the particular arguments found in jurisprudential literature and assesses each of them individually. ${ }^{9}$ This makes for a longer, and perhaps more laborious, discussion, but given the comprehensiveness of my case against conceptual jurisprudence, this approach is inescapable.

To illustrate this last point about the need to take individual arguments on their own, I will begin with a view that at first blush may appear to be entirely congruent with Leiter's. Cognizant perhaps of the bad reputation of conceptual analysis in contemporary philosophy, several legal philosophers have argued that it is a mistake to think that jurisprudence has much to do with conceptual analysis at all. I have no doubt Leiter intended his critique to capture the

\footnotetext{
${ }^{5}$ In addition to Quine see, for example, Gilbert Harman, Reasoning, MEAning And Mind, at ch. 5-7 (i999); Jerry Fodor, RePresentations: Philosophical Essays on the Foundations of Cognitive SCIENCE (I98I).

6 Brian Leiter, NATURAlizing JURISPRUdence: EsSAys ON AMERICAN LEgAL REALISM AND NATURALiSM in LEGAL PhiLOSOPHY i75-76 (2007).

${ }^{7}$ See, e.g., Graham Oppy, Book Review, 8o Australasian J. Phil. 384, 386 (2002) (reviewing New Essays ON THE A PRIORI (Paul Boghossian \& Christopher Peacocke eds., 200o)) ("if the essays in this book are anything to go by, there does seem to be an emerging consensus that Quine's rejection of the a priori on the basis of an undiscriminating blanket pragmatism is no longer tenable: even if there are reasons for being skeptical about the a priori, those reasons are not the ones upon which Quine relied.").

${ }^{8}$ This strategy is explicitly employed against Leiter in John Oberdiek \& Dennis Patterson, Moral Evaluation and Conceptual Analysis in Jurisprudential Methodology, io CuRRENT LEGAL Issues 6o, 72 (2007).

${ }^{9}$ An approach more similar to the one taken here, although developed in a rather different way, is found in Aaron J. Rappaport, On the Conceptual Confusions of Jurisprudence, 7 WASH. U. JURISPRUDENCE REV. 77 (20I4). A very helpful discussion of some of the terrain covered here is also Nicos Stavropoulos, Hart's Semantics, in HART'S POSTSCRIPT: ESSAYS ON THE POSTSCRIPT TO THE CONCEPT OF LAW 59, 69-79 (Jules Coleman ed., 20oi).
} 
work of these scholars, but so long as they claim that jurisprudence has little or nothing to do with conceptual analysis, they can declare criticisms of conceptual analysis, however sound, as having no bearing on jurisprudence. It is therefore important to examine these arguments closely and show why their arguments fail, why what are being presented as arguments dismissing conceptual jurisprudence are actually affirmation of it.

That is the task of Part I. Following that I turn to discussing the various senses of conceptual jurisprudence. I distinguish between two families of views, which I call "externalism" and "internalism." Roughly speaking, externalists think of concepts as entities that in some way exist outside (and regardless) of human minds, internalists treat concepts as building blocks of thought. Matters get even more complicated because there are different variants of each view. Parts II and III are thus dedicated to distinguishing between externalism and internalism, to explaining the different versions of each, and to pointing out what I think are their weaknesses. After concluding with that discussion I turn in Part IV to several residual issues that may explain both the attraction of conceptual theories of law and their enduring popularity. Part $\mathrm{V}$ concludes by hinting at possible alternatives to the currently dominant conceptual jurisprudence.

It goes without saying that I hope to convince readers that conceptual jurisprudence is not a viable enterprise, but I recognize that I am unlikely to convince everyone. I hope that even those who remain unconvinced will benefit from recognizing the need for greater clarity on what it is that they are doing when they engage in conceptual jurisprudence.

\section{Is Jurisprudence Conceptual?}

Several writers have recently criticized the suggestion that jurisprudence is conceptual. Jurisprudence, they say, is concerned with explaining "law itself," not the concept of law. John Gardner, for example, has written that "[t]he label 'conceptual' may give the unhappy impression that the object of study is the concept, rather than the thing of which the concept is the concept, in this case law." ${ }^{10}$ Michael Moore argued that "[g]eneral jurisprudence should eschew...conceptual analysis in favour of studying the phenomenon itself, law." 11 And Andrei Marmor claimed that analytic jurisprudence "is not an exercise in conceptual analysis." ${ }^{12}$ Instead,

${ }^{10}$ John GARDNER, LAW AS A LEAP OF FAITH: ESSAYS ON LAW IN GENERAL 276 n.I4 (2OI2).

${ }^{11}$ MOORE, supra note I, at 3II. Incidentally, contrary to Gardner, he contrasted his own objectivist approach with what he took to be the different, conceptualist, project that Hart was engaged in. See id. In a different chapter in the book, however, Moore says that "Hart is seeking to describe the phenomenon, law, with his sociology." Id. at 92. Given that Hart is, characteristically, far from clear on this matter, such confusions are not surprising.

${ }^{12}$ Andrei Marmor, Farewell to Conceptual Analysis (in Jurisprudence), in THE PHILOsophical Foundations OF THE NATURE OF LAW 209, 209 (Wil Waluchow \& Steffan Sciaraffa eds., 20I3) [hereinafter NATURE OF LAW]. 
he stated, "an explanation of law is an explanation of observable phenomena, even if the phenomena are of a social kind." 13 Plainly, if these views are correct, my challenge to contemporary analytic jurisprudence for its commitment to conceptual analysis is an attack on a straw man.

Marmor's suggestion is the most comprehensively argued, so I will start with it. It is a mistake to think that jurisprudence is concerned with conceptual analysis, he says, because the "the main methodological thrust of legal positivism is reductionism, not conceptual analysis." The reduction in question involves "offer[ing] an explanation of law in terms of something more foundational in nature, that is, in terms of social facts, which, in turn, can be explained by reference to people's actual conduct, beliefs, and attitudes." 14

As a description of the jurisprudential terrain this claim is revisionist in two senses. First, it flies in the face of much evidence that shows that many legal philosophers see themselves as engaged in conceptual jurisprudence: The most famous book in twentieth century jurisprudence is entitled The Concept of Law. When its author, H.L.A. Hart, reflected of his philosophical outlook he detailed his commitment to what he called "linguistic philosophy" and more specifically his indebtedness, above all others, to J.L. Austin, whose work focused on careful analysis of words and concepts. ${ }^{15}$ Marmor's claim also ignores Joseph Raz's statement in the opening pages of Practical Reason and Norms that the book was "primarily an essay in conceptual analysis," 16 and the numerous defenses (some of them discussed below) of conceptual analysis within jurisprudence. To defend his view Marmor must say that not only have critics of conceptual jurisprudence misunderstood jurisprudential debates, but that all these legal philosophers (many of whose substantive views Marmor actually endorses) did not understand what they were doing. Second, to say that the methodological thrust of legal positivism is a "metaphysical reduction" in the explanation of obligations in terms of individual attitudes implies that two of the most prominent legal positivists of the last century, Hans Kelsen and Joseph Raz, are non-positivists. ${ }^{17}$ Marmor is of course entitled to redefine the boundaries

${ }^{13} I d$. at 217 .

${ }^{14} \mathrm{Id}$. at 209.

${ }^{15}$ See $i d$. at vi; H.L.A. Hart, Essays in Jurisprudence And Philosophy 2-4 (1983) [hereinafter Hart, ESSAYS]; Hart Interviewed: H.L.A. Hart in Conversation with David Sugarman, 32 J.L. \& SOC'Y 267, 274, 275, 277, 282, 290 (2005) [hereinafter Hart Interviewed].

${ }^{16}$ See Joseph RaZ, PRACTICAL Reason AND Norms io (2d ed. i99o).

${ }^{17}$ See id. at 56-58 (criticizing Hart's account of legal rules for "depriv[ing] rules of their normative character"); $c f$. JOSEPH RAZ, BETWEEN AUTHORITY AND INTERPRETATION: ON THE THEORY OF LAW AND PRACTICAL REASON 50-52 (2009) (criticizing Hart's "naturalism"). That Raz's legal positivism is not motivated by "metaphysical reduction" is evident also from his statement that "[m]etaphysical pictures are, when useful at all, illuminating 
between positivism and non-positivism in any he wishes, but that suggests that the argument is revisionary rather than accounting for what one finds in jurisprudential literature itself. Moreover, there is a high price for this revision: By presenting the debate between positivists and non-positivists as a debate about legal reduction, Marmor implies that the fighting camps agree on what things count as laws and only disagree on the right way to explain those things, namely on whether one can explain them reductively or not. As is well-known, however, one of the things that positivist and non-positivists disagree about is which things count as laws (for example, the status of unjust laws).

On closer inspection it appears that Marmor's claims involve more a redefining of terms than a challenge to conceptual jurisprudence. When he says that jurisprudence is not concerned with conceptual analysis, it is because he gives the latter a rather unusual understanding, saying it is "not distinguishable from the meaning of words in a given setting." ${ }^{18}$ But that is just not how most people writing on concepts and conceptual analysis understand the term. When Raz recently said (repeating views he had expressed decades ago) that jurisprudence is not concerned with word meanings, he did not do so for the sake of distinguishing his work from conceptual analysis, for only a page later he went on to explain what concepts were (not word meanings) and explain the role of conceptual analysis within jurisprudence. ${ }^{19}$ Similarly, when Hart said that he was not seeking the meaning of words, he said this not in order to show that he was not doing conceptual analysis, but in order to distinguish what he was doing-conceptual analysisfrom lexicography. ${ }^{20}$ Once again, Marmor could attribute massive confusion to all those defenders of conceptual jurisprudence, because they did not really do what they thought they were doing. I will suggest, however, they are not confused; or rather, not on this point. When we examine what defenders of conceptual jurisprudence mean by the term, it turns out that they do (or attempt to do) what they say they are doing. The surprising finding is a different one: Marmor's views on what legal philosophy is about, presented (in the same essay) as an alternative for conceptual analysis, are in fact a defense of conceptual jurisprudence.

To make the case for the alternative, supposedly non-conceptual, understanding of jurisprudence, Marmor argues that legal positivism is primarily a theory about reduction. In

summaries of central aspects of our practices. They are, in other words, accountable to our practices, rather than our practices being accountable to them." $I d$. at 228.

${ }_{18}$ Marmor, supra note I2, at 213; accord id. at 2I2 ("An analysis of concepts is an analysis of the ways in which words function in our actual language games").

${ }^{19}$ See RAZ, supra note $\mathrm{I} 7$, at $53-56$. His denying that jurisprudence is concerned with word meanings goes back at least as far as JosePh RAZ, The CONCEPT OF A LEGAL System: An InTROduCtion to THE TheORY OF LEGAL SYSTEM 209-Io (2d ed. 1980). Yet, as mentioned earlier, around the same time Raz insisted he was engaged in conceptual analysis.

${ }^{20}$ See HART, supra note I, at 215. 
saying that, however, he confuses a general methodological commitment with a substantive view about law. Right at the beginning of The Concept of Law Hart stated that "neither law nor any other form of social structure can be understood without an appreciation of certain crucial distinctions between two different kinds of statement," ${ }^{21}$ namely internal and external statements. As these words make clear, Hart did not think this was a thesis about law; he took this to be a general claim about all social practices ("social structures" in his words). But Hart's book was not a book in the philosophy of social science. If it had been, it would not have had any claim to fame, for the distinction between internal and external points of view and the explanation of social practices in terms of individual attitudes was largely assumed in the book rather than argued for, and is in any case far from original to Hart. Whatever value The Concept of Law may have lies in its contribution to the understanding of a particular social practice. The central theses in the book are not claims about the right way to explain social phenomena, they are an explanation of a particular social phenomenon. Claims like that law is a "union of primary and secondary rules," or that " $[t]$ here are...two minimum conditions necessary and sufficient for the existence of a legal system," 22 are not methodological claims about reduction in the explanation of social phenomena (in general), and even if they presuppose certain ideas about the explanation of social phenomena, they themselves are presented as conceptual claims about law.

Moreover, many of the debates in jurisprudence have little or nothing to do with the question of reduction. For example, the debate between inclusive and exclusive legal positivists (to which Marmor contributed) cannot be about reduction, because much of it is conducted between scholars who share roughly the same views about reduction. Thus, even if one were to accept the claim that the main dividing line between positivism and non-positivism touches on the question of reduction, it leaves much of the jurisprudential terrain untouched. That terrain, I will argue, is conceptual.

Finally, Marmor presents reductionism as a methodological position that is somehow to be contrasted with conceptual analysis, but it is not immediately obvious that the two are in conflict. Frank Jackson's defense of "modest" conceptual analysis is offered as a necessary ingredient in his defense of reductive physicalism. ${ }^{23}$ This is particularly important in this context, because as will be discussed in more detail below, in the very same essay Marmor defends a view that is in important respects similar to Jackson's. Like Jackson, Marmor ends up

\footnotetext{
${ }^{21} I$. at vi.

${ }^{22} I d$. at $79, \mathrm{II} 6$.

23 See Frank Jackson, From Metaphysics to Ethics: A Defence of Conceptual Analysis i (i998) (defending "the importance of conceptual analysis for metaphysics" and more specifically to "(reductive) materialism or physicalism”).
} 
defending a version of conceptual analysis (albeit of a very different from Jackson's) as a preliminary step in a reductive account. ${ }^{24}$

We can set aside, then, the question of reduction as an irrelevant distraction. This does not yet answer the main line of argument of the scholars who say that jurisprudence is not conceptual. Jurisprudence, they say, is about describing or explaining the law itself, and not any "concept" of law. That was what both Gardner and Moore stated. Strictly speaking, however, these claims are clearly false. First, because any description of "law itself" would have to study a myriad of events, the behaviors and attitudes of a large number of individuals, and certain social and institutional structures. This is not at all what legal philosophers are interested in. For if legal philosophers, studying "the thing of which the concept is the concept," then their methods would have been plainly inadequate for the task at hand. Law, the "thing," is something that exists in the world, and so investigating it requires an empirical inquiry of things in the world, not the examination of abstract entities.

What Moore and Gardner are trying to provide is an account of all the properties those things in the world have in virtue of which they count as law. Only a page after Gardner's remark just quoted he says that "[ $t]$ he question of what it takes to qualify [as law], Hart's main question, is a classificatory one." 25 Marmor too, after dismissing conceptual jurisprudence, argues that substantive analytic jurisprudence (as opposed to its methodological assumptions) is concerned with identifying the "essential features" of law. ${ }^{26}$ That is a wholly different inquiry from the search for "law itself" or from explaining actual "social phenomena." It is, at most, an articulation of what something must be for the sake of explaining that social phenomena.

Furthermore, when one looks at how proponents of this view aim to do that, what we find is the familiar conceptual inquiry, conducted in the very same way as conceptual analysis, namely by examining our intuitions regarding certain thought experiments. Marmor, for example, specifies the method of discovering the essential features of law in the following way: "A feature of a social practice is essential to it if without it the practice would either not have existed at all or would have been radically different from what it is." And this, he tells us, is to

\footnotetext{
${ }^{24}$ Marmor presents the search for the essential features of law as a necessary step in the search for a reductive theory of law: "You cannot offer a reduction of a certain type or class of phenomena to some other type or class of facts unless you have a fairly robust sense of what constitutes the main features of the reduced class....If we want to offer a reductionist theory of law, we must have a pretty good idea of what is essential to law and what is only incidental and contingent." Marmor, supra note 18, at 222. Presenting the search for essential features of law as motivated by reductive goals is hard to square with the fact that anti-reductionist legal philosophers like Kelsen and Raz made essentialist claims about law. They clearly made those essentialist claims not as part of a program of reduction.

${ }^{25}$ GARDNER, supra note Io, at 277.

${ }^{26}$ See Marmor, supra note 12, at 222-25.
} 
be discovered by "ask[ing] whether a practice that is similar in all other respects [to law], but lacks [feature] $\mathrm{F}$, is still close enough to what we recognize as law in our society." 27

This is where the case for this alternative to conceptual jurisprudence collapses. To see this, one needs to notice two kinds of philosophical thought experiments. One kind, exemplified by some famous thought experiments in the philosophy of mind-what is like to be a bat, the Chinese room, Mary and her red rose, the zombies, ${ }^{28}$ and so on-are designed to act as reductios, showing the possibility or impossibility of certain claims about what things are in the world. They aim to do that by showing that a view must be wrong, because it entails an absurd outcome. Thus, such claims are intended to tell us what things in the world must or cannot $b e$. To examine the question of consciousness, for example, we are asked to imagine whether "philosophical zombies" are possible-whether creatures that are in every respect indistinguishable from humans but have no consciousness, can exist. Besides the vigorous debates on these questions themselves, ${ }^{29}$ there is a lively debate within philosophy on whether (or when) we can trust arguments based on such thought experiments. ${ }^{30}$

These, however, are not at all the kind of thought experiments Marmor and other legal philosophers have in mind. Here, the aim is to tell us what it takes to count as something. The best known examples of thought experiments of this kind are the so-called Gettier cases in epistemology. ${ }^{31}$ In these thought experiments we are asked to imagine a scenario and decide whether we should still call it an instance of "knowledge," or-if it any different-whether it is an instance of knowledge. That is conceptual (or analytic) epistemology, and it is its exactly legal counterpart that Marmor proposes is the primary task of jurisprudence. The thought experiments proposed by Marmor do not aim to ask whether a slightly-changed social practice he imagines (law without a certain feature we find in law in the real world) is impossible. The practices we are asked to imagine in order to examine the essential features of law are clearly conceivable, possible and not absurd. The only question the imagined social practice is supposed to help us answer is whether we should still call it "law," or-if it is any different-whether it is law. (Presumably if it is law, it is also correct to call it "law".)

${ }^{27} I$ d. at 224 .

${ }^{28}$ These thought experiments come, respectively, from Thomas Nagel, What Is It Like to Be a Bat?, 83 PHIL. ReV. 435 (1974); John R. Searle, Minds, Brains, and Programs, 3 BeHAV. \& BRAIN SCI. 4I7 (I980); Frank Jackson, Epiphenomenal Qualia, 32 PHIL. Q. I27, I30 (I982); DAvid Chalmers, The CONSCIOUS Mind 94-99 (1996).

${ }^{29}$ For a comprehensive discussion on the possibility of such "zombies" see Robert Kirk, Zombies, in STANFORD ENCYCLOPEDIA OF PHILOSOPHY, http://plato.stanford.edu/entries/zombies/ (visited on July I7, 20I5).

30 See, for example, the essays in Conceivability And Possibility (Tamar Szabó Gendler \& John Hawthorne eds., 2002). The title of this book demonstrates the aim and limits of such thought experiments, which is to examine the relationship between humans' ability to conceive certain things and their (im)possibility.

${ }^{31}$ See Edmund Gettier, Is Justified True Belief Knowledge?, ${ }_{23}$ ANALYSIS I2I (1963). 
This is what most people within legal philosophy call "conceptual jurisprudence," and this is the target of this essay. Thus, both what Marmor presents as an alternative to conceptual analysis and the method he proposes to answer his question are identical to those of conceptual legal philosophers. ${ }^{32}$ But since my debate is not over terminology, if one does not wish to call this inquiry "conceptual analysis," so be it: Call it "the search for the nature (or essence) of law." That is what Marmor, Gardner, and Moore think is a fundamental task of jurisprudence, and that (too) is the target of this article.

\section{Externalism}

We have reached the main course. I begin with a family of views I call "externalism." Conceptual jurisprudence is on this view a description of some abstract entity that captures what something needs to be in order to be law. Peter Hacker described this approach as "the analysis of objective (mind independent) concepts rather than 'ideas' or 'impressions'." 33 Because it is left unclear what those abstract, mind-independent entities are I start with a view I will, controversially, designate "Platonism." ${ }^{34}$ I will then turn to a variant of externalism derived from work in the philosophy of mind on the reference of certain concepts.

\footnotetext{
${ }^{32}$ See, e.g., RAZ, supra note $\mathrm{I} 7$, at $\mathrm{I9}$ (for Hart "there was no difference between an explanation of concepts and the nature of things of which they are concepts"); $i d$. at 20 ("I will follow [Hart] in equating complete mastery of a concept with knowledge and understanding of all the necessary features of the objects to which it applies").

${ }_{33}$ P.M.S. Hacker, The Rise of Twentieth Century Analytic Philosophy, 9 RATIO (n.s.) 243, 248 (1996). Hacker further described this form of conceptual analysis: "Chemical analysis displays the composition of chemical compounds out of their constituent chemical elements....Philosophical analysis harboured similar ambitions within the domain of ideas or concepts which are the concern of philosophy." Id. at 247. Hacker distinguishes this understanding of conceptual analysis from another that he thinks was the popular view in Britain after World War II (and so, presumably, the kind of conceptual analysis practiced by Hart) which he describes as the "giving a description, for specific philosophical purposes, of the use of a linguistic expression and of its rule-governed connections with other expressions by way of implication, exclusion, presupposition etc." Id. at 252. Here the aim of analysis in the sense of decomposition (modeled after chemistry) was abandoned in favor of "elucidation." $I d$. This is what the view I call "internalism," and which will be discussed in Part III, infra.

${ }^{34}$ Such views can perhaps be modeled after Frege's view of concepts as abstract propositions. See Eric Margolis \& Stephen Laurence, The Ontology of Concepts-Abstract Objects or Mental Representations?, 4I NoÛS 56I, 562-66 (2007). That Frege's views have unmistakable Platonistic undertones has not escaped notice. See, e.g., Tyler Burge, Frege on Knowing the Third Realm, IOI MIND 633 (1992).
} 


\section{A. Platonism ${ }^{35}$}

On this understanding of conceptual analysis, legal philosophers seeking to find the nature of law are trying to describe law's mind-independent nature. This is a plausible interpretation of Gardner's claim mentioned earlier that Hart was engaged in explaining "law itself": "Hart's enterprise," he said, is "that of clarifying the nature of law." This is not an empirical inquiry; rather,

[t] he question of what it takes to qualify [as law], Hart's main question, is a classificatory one. Thus Hart did not go, clipboard in hand to Nunavut or to Badakhshan or to the Ogaden, to see whether there were practices or attitudes on institutions there meeting the specifications set out in his book. He left such work to others with training in fieldwork. He merely advised on the practices and attitudes and institutions that the clipboard-bearers should look for, if perchance they were looking for law. If there were no such practices or attitudes on institutions to be found...it would only go to show that in some places and at some times life goes on without law. ${ }^{36}$

Presented in this way, what the philosopher does is not an empirical inquiry in any way: it is an exercise in determining the boundaries of categories that are completely independent of any individual's mental states. Whether things in the world match those categories or not is an empirical question, but one that can only be addressed after the conceptual classifier has completed her job.

Examples of endorsement of this view are also found in the work of Julie Dickson:

The legal theorist does not introduce a new concept in order to serve the intellectual ends of his own particular research project. Rather, he seeks to explain a concept of which people are already aware, and of which they make use in characterizing the society in which they live, and their own behavior and attitudes within it. ${ }^{37}$

[I]n explaining legal phenomena, the legal theorist himself has to be able to discriminate between and make evaluative judgments about participants' self-understandings in order to pick out which

35 In Danny Priel, The Boundaries of Law and the Purpose of Legal Philosophy, 27 LAW \& PHIL. 643, 652-54 (2008), I presented conceptual jurisprudence as committed to this view. Although it represents a significant strand within contemporary analytic jurisprudence, evidently I now think this characterization is too narrow. But I think what I say there is still a valid explanation of a way of making sense of that view.

${ }^{36}$ GARDner, supra note Io, at 277; see also Jules L. Coleman, Methodology, in THE Oxford HandBOOK OF Jurisprudence And Philosophy OF LAW 3II, 3I3 (Jules L. Coleman \& Scott J. Shapiro eds., 2002) ("Hart's aim is...to analyze the concept of law. To [do that] is, among other things, to rationalize the concept by articulating criteria for its use that enable us to be more precise than we could otherwise be in using the expression 'law'."). In the same essay, however, Coleman also presented the opposite relationship between philosophy and sociology of law, one in which sociology brings empirical findings which are the basis for legal theorists' analyses. See note 96, infra.

${ }^{37}$ Julie Dickson, The Central Questions of Jurisprudence, 56 CURrent LeGal Probs. 63, 89 (2003) (emphasis added). 
are most relevant in understanding law's important and significant features....[This is because s]ome self-understandings of the participants will be confused, insufficiently focused, or vague. Moreover, some self-understandings will be more important and significant than others in explaining the concept of law. It seems likely, for example, that understandings of features of law that are relevant to ultimately answering questions about law's moral value and ability to create moral obligations to obey will be among the most important self-understandings of participants. ${ }^{38}$

The first quote suggests concepts exist independently of humans who become "aware" of them. The second makes clear its commitment to this view by suggesting that some people may have incomplete or mistaken grasp of a concept. The concept is thus distinguished from people's (internal) beliefs or other attitudes about that concept, which may be mistaken or incomplete.

Another statement that indicate a commitment to a form of Platonism is found in Marmor's words that "nothing about the prevailing concepts of a practice or an institution really justifies this privilege of determining what is the true nature of the subject matter that calls for theorizing." ${ }^{39}$ And yet another comes from Gardner, who in response to the challenge to move with the time and deal with contemporary issues about law, replied: "why engage in the transient, when I can discuss the timeless?," Thus, in their search for the truth, Platonist legal philosophers are trying to articulate the nature of law itself, not people's potentially mistaken attitudes about what counts as law.

I hope it is now clear why I called this view "Platonism.” By using this term, I am bound to invite cries of foul, for these days Platonism looks like an obvious non-starter. ${ }^{41}$ Though not addressing this question directly, proponents of this view answer it by arguing that legal philosophers seek to discover features that are necessary or essential for the existence of law. This view is unproblematic if understood as a summary of what people take law to be, what people classify as law. But since externalists clearly think that this is not what they are interested in, it begs the question of what it is that they are essential features are of. It is thus difficult to see how this view avoids the extravagant ontology that makes Platonism so unpalatable. Unless these scholars go down the road of interpretivism ("these features are part of the best interpretation of our practices, and that best interpretation may elude everyone"), it is difficult (for me) to see what these essential features "describe" if it is not of some Platonic idea of law.

\footnotetext{
${ }^{38}$ Julie Dickson, Methodology in Jurisprudence: A Critical Survey, Io LEGAL THEORY II7, I38-39 (2004).

${ }^{39}$ Marmor, supra note I8, at 219. Marmor explicates what he takes interpretivism to be, but as I understand him, this is an aspect of interpretivism that he accepts. Earlier he endorses the same view himself: "Thought...even if it is collective and public, as revealed by language use-is never a guarantee of truth." Id. at 213. It is unclear to me how Marmor reconciles this statement with his ideas about constitutive conventions.

${ }^{40}$ GARDNER, supra note io, at 296 n.75.

${ }^{41}$ Marmor alludes to the fact that his view may be seen as Platonistic. See id. at $2 \mathrm{II}$ n.4. He is quick to deny the charge, but he does not explain on what basis.
} 
Nevertheless, it is possible to put these ontological concerns to one side and still show that there are serious problems with this version of externalism. What follows are several serious shortcomings of this view.

I. Circularity. Any attempt to discover the essential features of law, if it is not to be conducted in pure abstraction necessarily depends on a pretheoretical classification of certain things as law. It is the set of things that are laws that is supposed to provide the theorist with her initial set of features that she can then "test" in various thought experiments against imaginary practices. The problem is that things in the world do not come with a label "law" attached to them. So the philosopher cannot do any work on "the thing of which the concept is the concept," "the phenomenon itself," unless he has a way of knowing what things in (our) world are laws so that she could extract from them their essential features. For example, why do chairs do not count as a case of law? I am not asking this to be facetious or not suggesting that chairs are somehow borderline cases of law. My point is that in order to be able to say that chairs are not an instance of law, one must already have a theory, even if an implicit one, of what law is, of what makes something into law.

Proponents of this view seem to assume that there is pretheoretical agreement on what things happen to be laws, and that the only disagreement is on the correct account that captures those things. Indeed, such an assumption is essential for this inquiry, for if there is no such agreement, disputes about the true features of law are likely to be apparent disputes, the result of classifying different things as laws. The problem is that in reality there is no agreement on what things count as law, and as a result any claim regarding the necessity of any feature of law can be undermined by presenting a counterexample that does not have this feature and still counts as law. Since we do not have an agreed sample, there is no logical limit to the possible counterexamples, and consequently any claim to necessity is (necessarily) question-begging.

As this is a very important point, I will illustrate it with a few examples. Take, first, the dispute between "legal positivism" and "natural law." The way I am about to present it is in my view historically and philosophically confused, hence the square quotes. But it enjoys certain notoriety in jurisprudential circles, and so makes for a useful example. To simplify matters, let us assume that we take natural law to be the view that (grossly) unjust law is not "really" law, and legal positivism the view that the immorality of an edict has no bearing on its status as law. This debate cannot be settled unless you know in advance whether grossly unjust demands are laws: if they are (as a factual matter), then "legal positivism" is true; if they are not (as a factual matter) then "natural law" is true. But since what belongs in the object of inquiry is not fixed-it is exactly what the disputants disagree about - then they have no way of settling the dispute among themselves and no argument that one side adduces could challenge the other. The "legal positivist" can point at Nazi law and say: "look, this is unquestionably a law, and yet this is 
grossly immoral; hence unjust law can be law." But of course, this is only a counterexample if one assumes Nazi law is law; which is precisely what the natural lawyer can deny. The fact that it is law can only be true if one accepts positivist theory that defines law in such a way that Nazi law turns out to be law. But, of course, the legal positivist is not entitled to rely on this theory when trying to prove it. Notice that since this view seeks to identify what law is regardless of prevailing attitudes, which we assume may be confused and mistaken, the theorist is not entitled to rely on the fact (if it is a fact) that "most people" think of Nazi law as law (or not law) to settle this question.

This problem is not limited to this particular example, it is completely general. Here is one additional example. Gardner writes:

Natural law, in the tradition of that name, is not the same thing as human law. Natural law is the same thing as morality. It is the higher thing to which human law answers. We may regret that members of the tradition seem to feel a need to present morality as a kind of law, which it is not. For a start, morality is not a system (and is not made up of systems) and nor does it make claims, pursue aims, or have institutions or officials, all of which features are essential to the nature of law. ${ }^{42}$

This passage is thoroughly circular. Gardner informs us that the term natural law is a misnomer, because morality (what natural law really is) is not a system, does not make claims, or have institutions and officials, all of which are "essential" to the nature of law. Gardner does not argue here for a position, he presupposes it. For if morality is a species of law, then it shows that claims, institutions, officials (and so on) are not essential to the nature of law. To reach this conclusion all we needed was to find a central case of law that does not have all those features, and we found it: natural law. For the argument to go through in the direction Gardner presents it, he must know prior to making this claim and on independent grounds, that claims, aims, and so on are essential to law. On the basis of knowing that he can then conclude that what is called "natural law" is not really law. But he offers no such argument, because there can be no such argument. It is true that Gardner suggests at one point that central cases cannot be refuted by pointing to non-central counterexamples, ${ }^{43}$ but this claim will not help, for it is open for the natural lawyer to argue that natural law is a, even the, central case of law. I do not know of any non-question-begging way of refuting such a claim. Thus, Gardner's challenge only works by presupposing precisely what he needs to show.

Here is yet another illustration of this point. Scott Shapiro recently argued that law is a kind of a plan. Early on in his recent book Legality, long before he begins with his argument

\footnotetext{
${ }^{42} I d$. at 175 . Gardner does not provide any argument for any of these claims. Apparently, their truth is supposed to be self-evident.

${ }^{43}$ See id. at 152 ("It is part of the very idea of a central case that there might be cases...that do not exhibit all the features that make the central case a central case").
} 
explaining us what law is he describes the lives of groups of hunter-gatherers. "[Such b]ands are small collections of individuals that are generally mobile, have a relatively fluid membership, and subsist through hunting and gathering. They lack formal authority structures and are governed mostly by tradition, consensus, and persuasion by elders. Those who live in bands, in other words, don't have law." ${ }^{4}$

Though Shapiro presents the last sentence as a restatement of what was said before, it isn't. That conclusion only follows what was said before if one implicitly smuggles a view on what law is. This is, of course, the view that Shapiro will make explicit in later stages of the book. But that view cannot be right if bands have law. Do they? That is exactly the question that the conceptual inquiry seeks to answer. And since practices do not come with labels attached to them, it is perfectly possible to offer an account of law in which bands have law. We can, for example,

conceive of law in relative terms as the most fundamental or the most effectively organized set of conduct-imperatives in any society, one might with perfect consistency hold that the law of primitive Cheyenne society is to be found in popular customs of revenge, reciprocity, and group-aid, but that the law of modern England is to be found centering in the activities of English courts. ${ }^{45}$

I cannot see any non-question-begging conceptual argument that will show this view of law to be wrong.

The problem all such conceptual claims suffer from can be analogized, perhaps imperfectly, to trying to solve a single mathematical formula with two variables. In our case one variable is what counts as law - the explanans - and the other is the theory of law-the explanandum. Just like in the algebra analogy, unless we can keep one of these variables constant, there is no single solution to the formula. To summarize this point: So long as there is no pre-theoretical agreement on what counts as law-on the thing to be explained-all essentialist claims about the nature of law are indefensible. The bad news is that we know that there is no such agreement, because legal philosophers engage in what they do in part in order to settle such disagreements. Consequently, beyond pointing out internal inconsistencies, all theories purporting to account for the essential features of law cannot be challenged in a non-circular way. ${ }^{46}$

${ }^{44}$ SCOTT J. SHAPIRO, LEGALITY 35 (2OII).

${ }^{45}$ Felix S. Cohen, Book Review, 53 HARV. L. Rev. 707, 708-09 (1940). Cohen is not the target of any of the arguments made in this essay, for in his mind, what counts as law is to be measured by whether it "is useful or useless. It is not true or false, any more than a New Year's resolution or an insurance policy." Felix S. Cohen, Transcendental Nonsense and the Functional Approach, 35 CoLUM. L. REv. 809, 835-36 (1935).

${ }^{46}$ Marmor alludes to this circularity but argues that it afflicts other approaches, such as Dworkin's interpretivism. See Marmor, supra note I2, at 222-23. Even if he were right about this, that would hardly vindicate his position; at most, it would show that interpretivism fares no better than his own view. But in any case, he is wrong. 
It might be thought that the situation is not as bad as I just suggested, because there is no perfect freedom in choosing what belongs to the object to be explained. Even if there is no complete pretheoretical agreement on what things are law, there are still paradigmatic or noncontroversial cases of law, and that their existence suffices for validating the kind of thought experiments aimed to discover the nature of law. In somewhat different ways both Gardner and Marmor say something along these lines. Marmor says that the essential features of law are only exhibited in "central cases" of law; Gardner may be going further in saying "no number of supposed counter-examples can show that a proposed paradigm is not a paradigm. That is because a paradigm or central case is simply the case that shows how the other cases-including those supposed counter-examples-ought to be." ${ }^{47}$

Looking at central cases, however, will not help evade this problem. Marmor acknowledges that what counts as a central case could be vague and that there may be borderline cases, but the problem with this view has little to do with vagueness. If no number of counterexamples shows that a paradigm case is not a paradigm, then one has to give an account of what does make for a paradigm case. Are we just supposed to "see" that certain cases are central? If this is the case, what are we to do when two different people claim to see different cases as central? To illustrate how unreliable the seeming obviousness of "central cases" consider the case of Hart. Hart treated state law as a central case of law and "international... and primitive law" as less central cases. ${ }^{48}$ As a result, he treated features he found in the former as essential features of law, even if they are not found in the latter cases. But there is nothing "natural" or "neutral" about that determination: it may reflect Westphalian views dominant in his time, it may appear natural to someone who practiced law in I930s England. "Central" here simply means heuristically available. To remain descriptive, to avoid the charge of simply designating what one is familiar with as "central," one has to have a theory of what counts as a central case, and how we come to know that, in a way that does not smuggle in one's desired conclusions. The problem with taking the law of a modern, western, state as the paradigm case of law is that it necessarily introduces such assumptions on "what it takes" to be law, before the inquiry that is supposed to discover them, begins. The assumption is either a substantive one (simply taking municipal law to be a central case), or it is a methodological one (the central case is the case taken by most people to be central, which, itself simply the product of the contingent facts of the world they

Interpretivism starts with empirical observations about what people classify as law and escapes the circularity by engaging in an unabashedly normative inquiry. See RONALD DWORKIN, LAW's EMPIRE 64-66 (I986).

${ }^{47}$ See Marmor, supra note I2, at 224; GARDNER, supra note Io, at 152.

${ }^{48}$ See HART, EsSAYS, supra note 15 at 89 ("although there are central clear instances to which the expressions 'law' and 'legal system' have undisputed application, there are also cases, such as international law and primitive law, which have certain features of the central case but lack others"). 
happen to find themselves in these days). As it happens, neither way is actually defended in the conceptual jurisprudence literature, and within the externalist perspective discussed here, neither is defensible.

2. The inadequacy of human intuitions for discovering "real" essences. A further, related, problem with this view is that the proposed method for discovering the essential features is woefully inadequate for its purported task. Marmor suggests that examining our intuitions against imaginary cases will find the essential features of law; Gardner's views exemplify this approach. But the proposed method asks humans who come to the inquiry with their human classifications (which by externalist hypothesis they can all get fundamentally wrong), to evaluate imaginary cases in order to discover the real essential features of law (and not the essential features of a certain, contingent, buman classification). For this method to be reliable, investigators have to be able to know whether their intuitions reveal their human classifications (i.e., the features of the human category) or the real classifications (i.e., the real essential features of law). Proponents of this view have not acknowledged the problem, let alone suggested a way of separating the former from the latter.

A related methodological problem is that if intuitions could somehow discover a reality that exists beyond human classifications, there is the problem that different people have different intuitions on what counts as law. To overcome this problem, we would have to know whose intuitions are more reliable. When Dickson said that "some self-understandings of the participants will be confused, insufficiently focused, or vague," her unstated assumption seems to be that philosophers of law, perhaps because they think harder on these questions have better access to the "full" understanding of concepts, have a way of discovering others' errors, or that their intuitions are somehow more reliable. Reality does not support this assumption. Whatever disputes exist among the general population about what counts as law are in no way eliminated or reduced within the ranks of legal philosoophers. On the contrary, the very same diversity of views found among non-philosophers are multiplied with numerous additional views and shades of views when philosophers begin debating them. And since on this view there is no higher authority above one's intuitions, different theorists can play without end the game of presenting their intuitions as the nature of law, and resisting other philosophers' different intuitions with question-begging argument. The only remarkable thing about this activity is that it is somehow considered "profound" and in some way important.

3. The possibility of different and conflicting concepts. A further underlying assumption of the view that people may have an incomplete or mistaken grasp of their concept is that there is one concept that different people are trying to articulate. But this is an unwarranted assumption. Concepts on this understanding are abstract entities or theoretical constructs, which implies that there is an infinite number of them. How are we to tell whether a person has an incomplete 
grasp of a certain concept or a complete grasp of another? This is a crucial question for the viability of jurisprudential essentialism, but it is one that proponents of this view do not address at all. Just as there is a set of essential features of law, there is a set of essential features of another, somewhat similar institution, schmlaw. And so what may be an incomplete or partly mistaken grasp of the concept LAW may be a complete grasp of the concept SCHMLAW. How are we to tell those apart? Language will tell us nothing. The person who has a complete grasp of the concept SCHMLAW will use the word "law" when referring to schmlaw, so linguistic usage will not help. It is possible, and may explain many legal (and jurisprudential) disputes, that some members of a community refer to law when they say "law" while others refer to schmlaw. And of course there may be whole communities that when they use the word "law" (or its translation) refer to schmlaw.

Surprisingly little attention has been paid to this possibility, although it has real significance for understanding jurisprudential debates. One way of looking at the situation is that it presents us with two hypotheses about jurisprudential debates. In one, there is a single concept LAW, and so disagreement about it implies that at least one person has an incomplete or erroneous understanding of the concept. In another, the disagreement is only apparent, because different people use the same word ("law") to talk about different things. Which of these two hypotheses better reflects reality? If we present a challenge to someone's views on law, and she admitted her error and revised her views, we would have good reason to conclude that the person in question had a partial grasp of the concept the philosopher is trying to describe. But if the person in question refuses to alter her views even after we made sure she understood the challenge, it is more plausible that she is trying to grasp (and perhaps even succeeding) a different concept. It does not take much effort to notice that jurisprudential debates resemble the second scenario more than the first. ${ }^{49}$

The last paragraph considered disagreements among legal theorists, but the same conclusion is possible even when contrasting the theorist's view with those of lay people. Suppose it turns out that the theorist's view does not match those of most of the population. To make this example more concrete, consider the fact that Hartian positivism implies that a crime organization that terrorizes people into obedience is, under certain conditions, a legal system. This may seem surprising, because one of the presumed difficulties with Austin's account is that it implied that law was the gunman situation writ large. Nevertheless, Hart's positivism leads to an outcome that is not significantly different. The explanation, briefly, is as follows: what makes something into law, for Hart, is that there is a group of people that accepts a certain set of rules; all others governed by these rules may do so completely out of fear of sanction. As long as the

49 For a more detailed exploration of the challenge posed by persistent disagreements to descriptive jurisprudence see Dan Priel, Jurisprudential Disagreements and Descriptivism, 8 PROBLEMA 483 (20I4). 
crime organization develops a certain institutional complexity, it is, for Hart, a legal system. ${ }^{50} \mathrm{I}$ venture to guess that for many people (as well as some legal theorists) a crime organization of that kind would be a paradigmatic case of something that is not law. Dickson's arguments suggest that either Hart or his detractors should revise their views: someone simply has not thought hard enough about what law is. But would anyone be required to change their views after reading Hart? Clearly not, because an "erroneous" view about the concept LAW may be a perfectly correct view about the concept SCHMLAW.

The problem also occurs in the context of making intercultural comparisons. Gardner's "classificatory" claim, recall, is that the legal theorist seeks to find what properly belongs to the category of law, what makes something into law. This find, he said, the legal theorist can deliver to empirical social scientists, who then to go to the world to find where this category is instantiated. If they happen not find the concept instantiated in some communities, says Gardner, "that would be no skin off [the legal philosopher's] nose. For him it would only go to show that in some places and at some times life goes on without law." 51

Though Gardner presents this as Hart's view, I think this is quite clearly not what Hart thought he was doing when he described his book as "an exercise in descriptive sociology." 52 Considered on its own (and this is quite clearly Gardner's own view), it implies that jurisprudence is less than useless. Here is why: If Gardner is to be consistent, he must give the same answer even when the product of the legal philosopher's labors is not instantiated in any place. The theorist cannot assume that what is found in his society is law, that his society is the standard against which other, faraway societies need to match. It follows therefore, that just as the legal philosopher can hand his findings to the anthropologist who goes to "Nunavut or to Badakhshan or to the Ogaden" to find out whether they had law, he similarly hands over his findings to the anthropologist who goes to check England, France, or the United States. And if the anthropologist finds no law there too, that would still be no skin off his nose. And the same is true even if all anthropologists return finding no law anywhere. After all, on this view the philosopher just offered a classification, independent of any empirical assumptions, and if it so

${ }^{50}$ See HART, supra note I, at II7. As this example does not turn on a question of Hart exegesis, those who think I described Hart's views incorrectly, can use Kramer instead, for he explicitly endorsed this view. See MATTHEW H. Kramer, In Defense of Legal Positivism: LAW Without TrimmingS 99-io8 (I999).

${ }^{51}$ GARDNER, supra note Io, at 277 .

${ }^{52}$ HART, supra note I, at vi. Admittedly, later in life Hart said: "What I should have said is that [The Concept of Law] provides the tools for descriptive sociology, not that it is descriptive sociology." See Hart Interviewed, supra note I5, at 29I. But I think that here his earlier claim to be doing "descriptive sociology" is a more faithful account of what he intended to do in The Concept of Law than his later remarks, which were made in response to heavy criticism. My discussion in the text shows why this later view is extremely implausible. In Part III.A, infra, I present what seems to me a more likely interpretation of Hart's actual view. 
happens that there is nothing in the world that fits that classification, that would not show his classification to be wrong. If the inquiry in question is truly conceptual (or "classificatory") no empirical evidence could challenge it.

It is in this sense true that if it turns out that there are no instantiations to his classification, the legal philosopher can go on unperturbed. There is, as I said, an infinite number of possible classifications, and the philosopher can choose to explain whichever one fits his fancy. But the legal philosopher's choice of which classification to describe matters only if it tells us something about the things in the world people call "law." Unless this is so, choosing one concept and explicating it is not just futile but completely arbitrary. (What is not arbitrary is the decision to designate it the concept of law, even though it is not instantiated in the practices humans call "law.")

To see the kind of problem that this view entails, consider the following question: Do chairs belong in the same category as laws? The right answer is, "It depends." Here are two categories to which they arguably both belong: the category of things that exist, and the category of human artifacts. And even though (as mentioned earlier) Gardner thinks that natural law is not law, because it does not contain, among others, institutions, even he thinks that morality (natural law) and positive law both belong to certain categories, for example, things that contain norms. So on some perfectly valid classifications law and morality belong to the same category. In fact, there is an infinite number of categorizations which include positive law but not morality (or vice versa), just as there is an infinite number of categorizations in which they are both included, and an infinite number of categorizations to which neither belongs. Unless the theorist aims to provide some external control for what belongs to a particular category, say, by trying to articulate the classification that most humans employ, the enterprise of designating a particular category (which according to Gardner is not fixed by any assessment of "statistically preponderant cases") $)^{53}$ is completely arbitrary, and the findings completely trivial. It provides literally no illumination on any human practice. It is not because there is no classification that captures law-according-to-Gardner; there is such a classification, just as there is a classification of law-according-to-Cicero or law-according-to-Dworkin as well as law-according-to-Joe-Smith.

Unless a legal philosopher can explain why he chose to describe the concept or classification he did (out of all possible others), we would have to conclude that his classificatory efforts are utterly useless for it "describes" a concept with no worldly instantiations. Why should we have any interest in that? Why did Hart waste his talents on describing this concept and not one of a literally infinite number of other concepts with no instantiations? This explains why

${ }^{53}$ GARDNER, supra note Io, at $5_{52}$. 
Gardner's defense of Hart's work dooms it, and why it also misunderstands it. Hart tried to address "persistent questions" about a familiar social practice, an "institution, [that] in spite of many variations in different cultures and in different times, has taken the same general form and structure" in all of them. ${ }^{54}$ It follows that for Hart's book to be valuable there must be some fairly common instantiations of it in the world. That is, of course, what Hart thought, as he took it for granted that those things that "educated people" 55 treat as specimens of law ("English law," "American law," "Roman law"), that what is called "droit" in France, and "derecho" in Spain - are all instances of law, and that they are all instances of the same kind. But to say that is to try and assess this buman category, to engage in a very different from the one Gardner has in mind, one that is at bottom sociological. ${ }^{56}$

In trying to distinguish the philosophical inquiry from a sociological one, Gardner, if he is serious, must not allow any empirical information in, no "central cases" of law, not even word meanings and linguistic practices, as they can merely tell us what people think law is. The problem is that so understood, the enterprise of describing "law in general" (as Gardner entitled the chapter from which these words come) becomes true by definition. It is, literally, irrefutable, and as such, vacuous.

Of course, in reality no legal philosopher engages in this pure inquiry, and all smuggle in certain assumptions on what law is based on certain views about real-world instantiations of law. But once these are allowed in, it shows that the philosopher is in fact beginning his inquiry with a stock of examples based on his anecdotal "clipboard-bearing" inquiries into what things count as law in his own society. Once those are allowed in, however, it is hard to see how the theorist can avoid engaging in more "clipboard-bearing" inquiries before proceeding with the search for the nature of law, so that he can know that the assumptions prevailing in his society as to what count as law are in fact correct. To say that, however, is to reject this non-empirical, pre-sociological version of externalism.

\section{B. Externalism about Reference}

Some defenders of descriptive jurisprudence have tried to explain what it is concerned with, and in what way it is different from accounting for people's attitudes, by relying on ideas from philosophical work on reference, especially in relation to natural kinds such as gold or water. The main inspiration here has been the work of philosophers Hilary Putnam, Saul Kripke, and

\footnotetext{
${ }^{54}$ HART, supra note I, at I, 240.

${ }^{55} \mathrm{Id}$. at 3 .

${ }^{56}$ See Section III.A, infra, where I discuss what I take to be Hart's actual approach.
} 
Tyler Burge on the relationship between meaning and reference. ${ }^{57}$ In jurisprudential literature one can identify two somewhat different versions of this view, one defended by Michael Moore, the other by Joseph Raz. Moore is closer to the views of Putnam and Kripke, Raz to those of Burge. I will examine their arguments in turn. My conclusion is that whatever value these views may have in other areas, they do not suffice to vindicate the search for the nature of law.

\section{(a) Explaining Law as a Functional Kind}

When one speaks of, say, gold, there is probably something in one's head (some image of a yellowish metal, some thoughts about its preciousness) but these things do not determine what one is talking about. One may speak about "fire" and refer to fire even though what one has in one's head (what, if you wish, one means by the word "fire") is completely wrong. After all, people who lived in ancient or medieval times successfully referred to fire despite the fact that they had no idea, or very wrong ideas, about what fire was. If what is in one's head that determines what one refers to, we would have to conclude that people who thought that fire was the result of escaping phlogiston were not referring to anything, as phlogiston does not exist. And we would have similarly to conclude that when they spoke of fire and we speak of fire we refer to different things. And yet, it is plain that when these people talked about "fire" they succeeded in referring to fire, and that the thing they referred to was the same as what we refer to when we talk about "fire." The implication of this view is that at least with regard to some objects, when we talk about them, what fixes the reference (i.e., what determines what objects we talk about) is not what "it's in our head" but what the thing really is. The significance of this idea is that to fix the reference (the object) of some things human speak about, we need to know what they really are, not what humans think they are.

Michael Moore has sought to extend these ideas to jurisprudence:

[O] ur concepts do not determine the reference of terms like 'gold' or 'law'. Rather, the theory is one of 'direct reference' whereby 'law' refers to law without some third thing intervening. The meaning of 'law', on this theory, is given by the nature of the thing referred to-law-and not by some concept of law that fixes (by linguistic convention, or 'analytic necessity') what can be law. ${ }^{58}$

It is clear from this and other passages that Moore associates his position with the ideas of Kripke and Putnam. But he presents a misleading formulation of this view; of course there is something else "intervening." The word "gold" refers to gold (i.e., to whatever gold happens to be) only by way linguistic convention; without that convention the word "gold" is nothing but a

\footnotetext{
57 The central works here are SAUl A. KRIPKE, NAMING AND NeCESSITY (I980); Tyler Burge, Individualism and the Mental, 4 Midwest Stud. In PHIL. 73 (1979); Hilary Putnam, The Meaning of "Meaning", 7 MinN. STUD. IN PHIL. SCI. I3I (I975).

${ }^{58}$ MOORE, supra note I, at 3ro.
} 
bunch of ink scrawls. If the word "gold" refers gold, this is because humans want it to refer to it. It is not just that the word "gold" could refer to silver or water or law. The word "gold" could also refer to any yellowish, malleable metal, which conducts heat and electricity and so on. If that's the case, the reference of "gold" would not be to what gold really is (a metal with a certain microphysical composition), but to whatever has certain superficial, external, features, whatever its chemical composition happens to be. The latter concept is not inconceivable, and we can invent a word (say, "goldish") to refer to it. If this is true, it is an empirical question whether the word "gold" refers to gold (i.e., whatever has the microphysical structure of gold) or to anything that has the superficial features of gold. Similarly, it is perfectly possible that when some people use the word "water" the concept they have in mind is WATERY STUFF, namely anything that has superficial features of water (liquid at room temperature, quenches thirst, sustains life, and so on) whatever its microphysical structure happens to be. It is therefore an empirical matter what our words refer to, and Moore cannot assume otherwise.

Moore's error can be gleaned from another passage:

[T] he only things whose nature is fixed by our concepts are 'things' that do not exist-Pegasus, the twentieth-century kings of France, and the like. There are no things referred to by such terms, so such words' meaning can only be given by their concepts. Pencils, law, co-ordination solutions etc., do exist and thus can have a nature that gives meaning of their respective words. ${ }^{59}$

Moore argues that because Pegasus does not exist the meaning of the word "Pegasus" is determined "by [its] concept," by which I suppose he means, by people's beliefs about the matter. But that winged horses do not exist is an empirical, a posteriori finding; and our present beliefs (that such creatures do not exist) can turn out to be false. Suppose we discovered one such creature tomorrow. Would that discovery immediately change the reference or meaning of the word "Pegasus"? Would this mean that when the Greeks spoke of "Pegasus" they referred to this newly-discovered creature? I cannot see why it would, for even if such a creature existed, it does not follow the word "Pegasus" was intended to refer to it. The existence of winged horses does not entail that the references of "Pegasus" is fixed by what those creatures happen to be. The same is true of "water." The fact that water exists tells us nothing about the wholly separate empirical question of the meaning or reference of "water." Humans can invent categories as they wish and use words to refer to those categories; whether the words they use refer to "natural" or "invented" categories depends on their preferences.

All this matters for jurisprudence, because, even if one accepts all else that Moore says about law, Moore assumes without warrant that when people use the word "law" they refer to this thing whose nature legal philosophers seek to discover. Without empirical evidence he is

${ }^{59} \mathrm{Id}$. at 3 II. 
not entitled to this assumption. If this is not the case, then the entity Moore described, though interesting, has no bearing on understanding the human institution of law. In that case it is incumbent on him to explain to us why he chose to describe it and why we should have any interest in it.

But we have reason to doubt Moore's arguments at an even earlier stage, and we can do this on the basis of his own arguments. There are things that exist but whose reference is, to use his terminology, fixed by our concepts of them. Moore himself gives an example of one such thing: Figueroa Street in Los Angeles. He gives it as an example of what he calls a "nominal kind," which is something whose "nature is given by the common label attached to its various specimens." ${ }^{60}$ That implies that even by Moore's own lights, the claim quoted earlier ("the only things whose nature is fixed by our concepts are 'things' that do not exist") is false. Figueroa Street exists but what it is is fixed by what people think it is.

If such kinds exist, how do we know that law is not such a kind? Moore's answer starts with noting that we use different words to refer to law in different languages. But, he says, if law were a nominal kind, then "[g]eneral jurisprudence could only be a language-specific study, so that there would be an English general jurisprudence, a French general jurisprudence, etc." ${ }^{61}$ As it happens, I believe that jurisprudence is a far more culture-specific than most proponents of "general" jurisprudence assume, ${ }^{62}$ as evidenced by, for example, the relative isolation of Englishlanguage jurisprudence from (say) French-language jurisprudence (or even jurisprudence by French scholars when writing in English). But even by Moore's own lights, this response is unconvincing. Consider again Figueroa Street, which Moore assumes is a nominal kind. If his argument were true, then those who speak of Figueroa Street and those who speak of derecho Figueroa would be speaking of different things, just as those who speak of Fifth Avenue and those who speak of di wu dadao (in Mandarin). In fact, even among English speakers, if this argument were sound, those speaking of Sixth Avenue and those speaking of Avenue of the Americas would be speaking of different things. So the existence of general jurisprudence and references to law in different languages in no way challenge the possibility that law is a nominal kind.

After these preliminaries, let us consider Moore's actual argument. He presents the outline of his argument as follows:

(I) Some thing $\mathrm{X}$ is law only if it serves the distinctive function(s) of law.

(2) The distinctive function (s) of law is Y.

\footnotetext{
${ }^{60} I d$.

${ }^{61} I d$. at 3 I2.

${ }^{62}$ See Dan Priel, Is There One Right Answer to the Question of the Nature of Law?, in NATURE OF LAW, supra note I2, at $322,338-40$.
} 
(3) $\mathrm{Y}$ is served only if $\mathrm{X}$ obligates.

(4) Therefore, something is law only if it obligates. ${ }^{63}$

Premises (I) and (2) are the crucial ones. If I understand him, Moore thinks that (I) is an a posteriori discovery, but unless he means to base this finding on people's attitudes (which he clearly does not), I cannot see what kind of empirical investigation led him to it. Similar concerns afflict (2). For the analogy with natural kinds to be valid, (2) has to be an a posteriori discovery, but I do not see what kind of empirical investigation could, even in principle, lead to this conclusion. Moore writes that to know the function of law requires "nothing less than a full theory of the good and the right." Armed with it one can decide "what could be what a legal system is good for." ${ }^{\prime 4}$ Even supposing one can discover (I) by empirical investigation and then in a similar fashion also learn the correct list of goods (which seems to be Moore's view), one will have to determine which goods should be supported by law, but the answer to this will be, at least in part, determined by (rather than determine) what law is, for only after we know what law is can we know which goods can be supported by law.

After filling in the details of his proposed schema, Moore has concluded that unjust law is not law. That, he believes, is a true fact about law in the same way that water is $\mathrm{H}_{2} \mathrm{O}$ is true of water. Suppose, however, he were to meet a group of individuals that talked about unjust laws; he would have to tell them, presumably, that he has made a discovery, namely that there is no such thing as an unjust law. How would they react? They could simply say, "what we mean by 'law' captures any prescription by a sovereign whatever its content." I cannot see what he could tell them in response. First, they can use the word "law" to refer to anything they want. Admittedly, in this respect he is in no worse position than the scientist; for language users could reply that in using the word "water" they have in mind watery stuff, and they would not be wrong. But the similarity between the two cases is limited, and the expert in the case of law fares worse, for a reason that by now should be familiar. Unlike the case of water, in which the expert can say, "you wish to refer to this substance," while pointing at a specimen of water, "so let me tell you (based on my expertise) what it is," there is no comparable specimen that can be pointed at in the case of law. At most all that we can point at are paradigm cases ("if something is a law, that one is"). But we have already seen that what counts as paradigm cases is not selfdetermining or uncontroversial.

A more serious problem with Moore's argument is that unlike the scientist who earned his expertise, the legal philosopher has not. The upshot of Moore's argument is that the determinant of the nature of gold is the natural scientist. For the analogy between law and gold

\footnotetext{
${ }^{63}$ Michael S. Moore, Law as Justice, SOC. PHIL. \& POL’Y, Winter 200I, at II5, II9.

${ }^{64}$ MOORE, supra note I, at 320.
} 
that Moore invokes to work, the actual search for the nature of law should be handed over to an empirical scientist. Just as the philosopher no longer tries to discover the nature of gold, so the legal philosopher should do in relation to law. But Moore wants the legal philosopher to occupy the role of the scientist in the domain of jurisprudence; and this is where the analogy breaks down. The scientist can point to the history of science and the successes of his claims to expertise, which gives her authority on the matter of the nature of water. The authority of scientists is not universally accepted, but there is no way one could seriously claim that legal philosophers have anything even remotely resembling scientific authority on the question of the nature of law. Without it, people will have no reason to defer to the philosopher's judgments on what law is.

My final point is more tentative. According to the view Moore follows, the designation of certain natural kinds begins with "ostensive definition," i.e. by pointing at an object and "baptizing" it as, say, "fire." This baptism can take place without knowing much on the object in question. What then happens is a long process of scientific investigation that yields new knowledge about that same object (or more precisely, about other specimens of the same kind). Thus, in the case of fire for example, the object-fire-does not change throughout the ages, while human understanding of it does.

That is why we can say that both the Romans and we refer to the same thing, even though what Romans thought about fire was wrong and is utterly different from what is in our heads. But in the case of a social institution like law, a different account is possible, namely that the object (law) changed and the concept changed with it. Conceptual change is thus explained not by gaining more knowledge about the same object, but by shifting the concept alongside with the object. On this account, the Romans were not wrong to hold certain views about law which fit their worldview and the practices. Rather, their social institution was indeed different from ours. There is a causal, historical, story to be told explaining the way the Roman institution became, in a slow evolutionary process, modern law, but this account does not require contemporary law and Roman law to be the same thing. Nietzsche called the investigation of such historical processes "genealogy." In the baptismal story of natural kind, the object stays the same while its explanation changes; in the genealogical story both the object and its explanation change.

Obviously, these last remarks need a lot of refinement to be evaluated; they may not be true at all. But since law, unlike gold, is a human creation, this is a possible explanation that Moore's views cannot rule out. This shows that the extending ideas that may have much merit in the context of natural kinds to the social institution of law is not straightforward. It requires both detailed philosophical argument and careful engagement with facts about the history of 
law before it can be made. In a way, then, we see once again that in jurisprudence the philosophical argument cannot be kept apart from empirical work.

\section{(b) Discovering Common Criteria}

Raz's views on jurisprudence have undergone a significant but underappreciated shift. In earlier writings Raz has argued that legal philosophy is concerned with "the necessary and the universal....Legal philosophy has to be content with those few features which all legal systems necessarily possess." ${ }^{\prime 5}$ Such remarks seem to place him in the pre-sociological camp of jurisprudence considered earlier. Some of his later remarks suggest that now he holds a rather different view: "The concept of law is part of our culture and of our cultural traditions. It plays a role in the way in which ordinary people as well as the legal profession understand their own and other people's actions. It is part of the way they 'conceptualize' social reality." 66 These words suggest that legal philosophy is not a distinct inquiry from sociology, but rather a form of cultural anthropology, one that aims to illuminate "our culture," and "to advance our understanding of society by helping us understand how people understand themselves." ${ }^{\prime 67}$

This shift in view has become even clearer in Raz's more recent writings. In these, Raz criticizes "individualism" as the view that describes the content of our concepts in terms of what is in an individual's head:

Where the individualistic approach goes wrong is in thinking that the criteria set by each person's personal rule for the correct use of terms and concepts are fully specified. In fact, their personal rules are not specified. Each person takes his use of terms and concepts to be governed by the common criteria for their use. That is all their personal rule says. The criteria that govern people's use of language are simply the criteria generally relied on in their language community for the use of those terms. People who think that they understand a term or a concept think that they have at least some knowledge of what the common criteria are. They may be wrong. They may be partially or completely mistaken about the common criteria. It is part of each person's rule for the use of the term or concept that mistakes can occur, for the rule refers to the criteria as they are, rather than to what that person thinks they are. What they are, however, does depend on what people think they are. The correct criteria are those that

\footnotetext{
${ }^{65}$ Joseph RaZ, The Authority OF LAW: EsSAYs ON LAW AND MORALity IO4-O5 (2d ed. 2009).

${ }^{66}$ Joseph Raz, Ethics in the Public Domain: Essays in the Morality of LaW and Politics 237 (rev. ed. 1994).

${ }^{67}$ Id.; $c f$. Jules L. Coleman, The Practice of Principle: In Defence of a Pragmatist Approach to LEGAL THEORY 179 (20OI) (conceptual analysis aims at "uncovering the most salient features of the concept: those that figure most prominently in an explanation of the kind of thing it is a concept of - that are central to our understanding and appreciation of it") (emphasis added).
} 
people who think they understand the concept or term generally share, ie those that are generally believed to be the correct criteria are the correct criteria ${ }^{68}$

Though this view bears important similarities to certain internalist positions that will be discussed below, I classify this view as externalist because it treats concepts as abstract entities whose content is external to any particular person's head. What's found in speakers' heads are the general criteria "relied on in" (and thereby fixed by?) a given community.

A significant advantage of this view is that it offers a fairly unmysterious answer to the question of what it aims to describe. Moreover, it explains certain features that are otherwise difficult to explain in some of the views mentioned earlier. For example, Raz's views can explain Dickson's claim about individuals' incomplete or mistaken grasp of a concept. Since for Raz the content of concepts is fixed by communal usage, the entire community cannot be mistaken about their concepts, even though individuals can. In this respect, Raz's views, although externalist, are at odds with the earlier types of externalism considered above, which allowed for global conceptual error.

Despite these advantages, this view is still riddled with crippling problems. There is no doubt that there is room for general work explaining the mechanisms by which meanings get fixed in a community, especially when there is no body with accepted authority for doing so. This is a topic which psychologists and cognitive scientists have been investigating; and it is an area to which philosophers of mind and language may help by considering possible models. This is clearly, however, not a topic that legal philosophers, as such, have much to contribute to. Legal philosophers are interested not in the general question of the way social meanings are created and fixed; they seek to explicate the content of those of shared criteria with regard to specific concepts in a certain domain of human life. Unfortunately, it is unclear how, and Raz in no way explains, the methods of philosophy can be of any help in this task. The contrast with Raz's earlier view is revealing. The older view posited a clear divide between the methods and aims of philosophy on one side and sociology on the other: Philosophy provides the few essential features of particular concepts, while sociology seeks to identify the contingent features that differ within particular instantiations of concepts. Raz's more recent view still seeks to maintain a division of labor between philosophy and sociology, but it is quite different from the

${ }^{68}$ RAZ, supra note I6, at 64 (all emphases added). What I say in the text is an attempt to present a fairly coherent view, but I have to admit that Raz's remarks on concepts are not well-articulated, and, as far as I can tell, not free from contradiction. For example, in the same book from which I just quoted, Raz also says: "baving a concept can fall well short of a thorough knowledge of the nature of the thing it is a concept of." Id. at 55. By talking about "having a concept" (instead of grasping one) Raz seems closer to using concepts in the internalist sense. In a different chapter Raz also says: "complete mastery of a concept [is] knowledge and understanding of all the necessary features of the objects to which it applies." Id. at 20-2I. This view seems closer to the Platonist discussed earlier. 
one he suggested in earlier writings. This new view has philosophy (together perhaps with cognitive psychology) provide a general account of concepts, and sociology provide information about particular concepts. But if that is the case, the explication and understanding of "our culture" as it is manifested in "our" concept of law falls squarely on the side of the empirical, sociological, inquiry.

Raz's newer view may explain the declining interest in general jurisprudence. If we take seriously Raz's claim that it is a "major task" of legal philosophy to explain "our culture," it is fair to say that legal philosophers have largely failed in fulfilling that task. I doubt anyone would recommend any of the familiar works of conceptual jurisprudence to anyone interested in "our" culture, even "our" legal culture. With jurisprudence so conceived, it is not difficult to see why: the kind of questions legal philosophers have been asking themselves and the methods they have employed to answering them are simply not up to the task. This is not just a matter of a mismatch between aims and methodology. Another problem, rather surprisingly for a discipline that puts such a high premium on precision and rigor, is that the aim and domain of its inquiry are so ill-defined. Raz assumes that within "our culture" there is one set of common criteria. If "our" culture is understood broadly to include people living in Western countries before the twentieth century (they are, after all, the classic exponents of "Western culture"), then the claim to common criteria is almost certainly false. Even if we narrow it down, it is not clear whether we can speak of a single set of common criteria within contemporary Western legal culture. It is, for example, a staple of discussions about legal cultures to distinguish between, at the very least, common law and civil law jurisdictions, and it is notable that the works of legal philosophers from civil law Western democracies are largely ignored in Anglophone jurisprudence, even when written in English. ${ }^{69}$ Even if we narrow our gaze further to look at the "culture" of Anglophone legal philosophy, we encounter in it divergences that are very difficult to explain in terms of misunderstandings of a single set of common criteria, but are easily explained in terms of conflicting criteria, themselves derived from conflicting moral and political ideals. $^{70}$

The deep irony about all this is that to the extent that legal philosophers present us with fairly determinate explanations of the nature of law so understood, they do so only by implicitly

\footnotetext{
${ }^{69}$ For the related problem of the need to provide a non-circular definition of what belongs to "our" culture see Danny Priel, Jurisprudence and Necessity, 20 CAN. J.L. \& JURISPRUDENCE I73, I85-87 (2007).

70 These differences exist among different common law jurisdictions, but also within a single common law jurisdiction. Cf. Matthew D. Adler, Social Facts, Constitutional Interpretation, and the Rule of Recognition, in THE Rule of Recognition And the U.S. Constitution 193, 224-25 (Matthew D. Adler \& Kenneth Einar Himma eds., 2009); Danny Priel, Trouble for Legal Positivism?, I2 LEGAL THEORY 225, 252-54 (2006) (arguing that the only way one might reconcile the idea of a rule of recognition with legal practice is by accepting that there are multiple, conflicting rules of recognition adopted by different members of society);
} 
interpreting the practice, by choosing which of the myriad of conflicting values and attitudes that make up "our culture" matter for the explication of law and then presenting a view of law in light of these normative choices. This, in broad outline, even if not in every detail, is Dworkin's interpretivism, exactly what most descriptive legal philosophers have adamantly insisted not to be doing.

\section{Internalists}

Let us turn now to the internalist version of conceptual jurisprudence. Internalists are those who use the term "concept" in roughly the way that cognitive psychologists use the term. On this understanding, and contrary to the way Hacker defined the domain of conceptual analysis, concepts refer to something like "ideas" or "impressions." Thus, for instance, Karen Neander, defined conceptual analysis as "an attempt to describe certain features of the relationship between utterances of the term under analysis, and the beliefs, ideas, and perceptions of those who do the uttering. It involves trying to describe the criteria of application that the members of the linguistic community generally have (implicitly or explicitly) in mind when they use the term." ${ }^{71}$

To give a better sense of conceptual internalism in its jurisprudential guise, consider the following statements coming from several defenders of conceptual jurisprudence:

The legal theorist does not offer conceptual analyses in order to show people how they ought to think about the law or to portray their thought process in the "best light." Rather, the theorist's aim is to represent the way that people actually think about the law. ${ }^{72}$

The targets of conceptual analysis are typically ordinary, or "folk," concepts....These concepts are by definition delineated by the situations to which "we" — the ordinary folk—take the word to refer. ${ }^{73}$

Conceptual analysis is the analysis of concepts;... [and] concepts are or correspond to mental ingredients needed to think about things of the relevant sort. ${ }^{74}$

${ }^{71}$ Karen Neander, Functions as Selected Effects: The Conceptual Analyst's Defense, 58 PHIL. SCI. I68, I70 (I99I) (emphasis added).

${ }^{72}$ Scott J. Shapiro, The Bad Man and the Internal Point of View, in THE PATH OF THE LAW AND ITS INFLUENCE: The Legacy of Oliver Wendell Holmes, JR. 197, 209 (Steven J. Burton ed., 2000).

${ }^{73}$ Ian P. Farrell, H.L.A. Hart and the Methodology of Jurisprudence, 84 TEX. L. REV. 983, 10oo (2006) (book review).

74 Kenneth Einar Himma, Reconsidering a Dogma: Conceptual Analysis, the Naturalistic Turn, and Legal Philosophy, ro Current Legal Issues 3, 4 (2007). 
Sometimes the commitment to conceptual internalism is somewhat less direct. Here is an example:

Take a certain legal system, say Roman law in the first century AD; let us presume that a certain norm, $P$, was recognized by the Roman lawyers of the time as part of and parcel of their legal system. Does it make sense to say that this community of lawyers has made a mistake, since according to the 'real nature' of law, $P$ did not lie within the extension of their legal system even then, despite their inability to recognize this? $?^{75}$

Does conceptual jurisprudence make more sense understood on these terms? This question must be broken down to two variants, which following Frank Jackson, it is now common to call modest and immodest. According to Jackson immodest conceptual analysis "draw $[\mathrm{s}]$...conclusion[s]... of what the world is like," or "given a role in determining the fundamental nature of our world." ${ }^{\text {"76 }}$ Modest conceptual analysis merely tells us "our ordinary conceptions" of certain concepts, "our folk theory of them." ${ }^{\text {"T }}$ The following two sections consider whether conceptual jurisprudence can be defended under either guise.

\section{A. Immodest Conceptual Analysis}

Most internalist defenses of conceptual jurisprudence maintain that it should be understood in its modest variant. ${ }^{78}$ As conceptual analysis has come under so much criticism, it is understandable why legal philosophers would be circumspect about making any extravagant claims about its powers. These days, to think that one could tell us what the world is like from the safety of one's armchair looks hubristic. In many of the most prominent examples of jurisprudential internalism, however, I think this is a case of false modesty. Hart saw himself as working from within what he called "linguistic philosophy," and when people these days refer to the heyday of this approach-Oxford in the I950s and 1960s-they often refer to think of it as an example of conceptual immodesty. Jerry Fodor gave the following example of the style of argument to be found in these writings: "the issue is whether there is survival after death, and

75 ANDREi MARMOR, INTERPRETATION AND LEGAL THEORY 74 (2d ed. 2005). Marmor makes his adherence to internalism even clearer when he follows the words just quoted with a discussion of the possibility that the concept of law is fixed by what law is in a manner similar to the way Putnam and Kripke have argued with regard to natural kinds. He rejects this view in no uncertain terms. $I d$. at $77-80$. Notice, that I discussed Marmor earlier as an externalist. See text accompanying notes 39-24, supra. As far as I can see, the views he discussed there are inconsistent with the views considered here.

${ }^{76}$ JACKSON, supra note 23 , at 43,44 .

77 Id. at 3I. In a more technical formulation Jackson defines modest conceptual analysis as central to "determining what to say in less fundamental terms given an account of the world stated in more fundamental terms." Id. at 44 .

${ }^{78}$ See sources cited in note 88 , infra. 
the argument purports to show that there can't be. 'Suppose an airplane carrying ten passengers crashes and that seven of the ten die. Then what we would say is that three passengers survived, not that ten passengers survived. QED."'79 This is, perhaps, a joke, but the idea that conceptual analysis tells us something about the world should not shock legal philosophers, who must be familiar with the following words:

When we examine what we should say when, what words we should use in what situations, we are looking again not merely at words (or 'meanings', whatever they may be) but also at the realities we use the words to talk about: we are using a sharpened awareness of words to sharpen our perception of...the phenomena. ${ }^{80}$

This passage by J.L. Austin impressed Hart enough to quote a part of it twice in The Concept of Law. ${ }^{81}$ What do these words mean? Austin's words acknowledge that words don't merely describe, but also construct. It is these constructions that enable us (to use his famous phrase) "to do things with words." Hart, similarly, wanted to use these methods not (just) for analyzing legal language, but to explain a social institution or structure.

How can conceptual analysis help in doing that? Hart's commitment to linguistic philosophy meant that he took the classification of the things he needs to describe to be captured, at least roughly, by the classifications made by people. He thought these classifications were not arbitrary, he thought it his job to bring the underlying reasons for these classifications to light, and he thought that paying careful attention to linguistic usage is a central means for doing so. It is fair to say that Hart saw himself as engaged in a sociological explanation (of sorts). He sought to understand a certain aspect of social reality and he thought that his approach (an inquiry from "the internal point of view") is a better way of doing that than the methodologies of "real" sociologists. As far as I can see, it can only make sense to suggest that one is engaged in this kind of sociological inquiry, that of explaining social institutions by way of analyzing linguistic practices, if linguistic practices (in some way) fix the boundaries of our practices. On this understanding, conceptual jurisprudence clearly presupposes conceptual analysis of the immodest kind.

Many familiar jurisprudential arguments are immodest in this way. When Hart distinguished between "being obliged" and "being under an obligation" he saw this distinction as crucial for understanding something about law itself. He used the distinction to delineate the boundary between law and the something that bears some resemblance to law. More broadly, he used the distinction between linguistic usage of law as reason (e.g., law used as a basis for criticizing those who fail to comply) and law as fact or cause (e.g., as a threat) to criticize the

\footnotetext{
${ }^{79}$ Jerry Fodor, Water's Water Everywhere, LONDON REV. BOOKS, Oct. 21, 2004, at I7, I9.

${ }^{80}$ J.L. Austin, A Plea for Excuses, 57 Proc. Aristotelian SoC'Y i, 8 (I956-57) (second emphasis added).

${ }^{81}$ See HART, supra note I, at vi, I4.
} 
command theory and the prediction theory. In both instances, the argument was used to tell us something about what the social institution of law is. Even when not overtly relying on linguistic usage, much legal philosophy is immodest in this way. Using thought experiments (e.g., on law in the society of angels, Swedes who are experts on American law), relying on "truisms" about law, and so on, these can all be seen as attempts to discover what legal practices are by way of a kind of sociological inquiry into people's attitudes about law, on the assumption that those attitude in some way constitute what law is.

In much of this literature the explicit aim is to discover the boundaries or limits of law. That seems plausible, as language is often revealing of the boundaries of human categories. ${ }^{82}$ Attention to language can be particularly helpful in revealing the boundaries of social practices, as those do not have physical boundaries. So understood, there is nothing wrong with the immodest of this enterprise for there is beyond human attitudes that determines the limits of law.

Despite the popularity of this kind of jurisprudential inquiry, I believe it is untenable. I will discuss three problems with it. ${ }^{83}$ First, it is unlikely that as a descriptive matter there are going to be attitudes on many of the boundary questions that have preoccupied legal philosophers. The reason is that there is no reason for people to have attitudes on the matter, since usually nothing depends on them. Even if one thinks that legal philosophy is pursued for its own sake and has no practical goals, legal practice is, well, practical. For this reason, practitioners will not worry themselves much about questions of boundary unless they have practical significance, and for the most part, they do not. This implies that for the most part the boundary questions that legal philosophers seek to solve by way of attention to language use or conceptual usage are likely to be indeterminate. Any conceptual analysis, modest or immodest, that aims to be a descriptively accurate account of the law, must acknowledge this fact and report it. Any attempt to go beyond those attitudes is no longer a description of linguistic practice.

The second problem is, in a way, the opposite. There are, no doubt, instances in which the question of boundary does matter. Leslie Green has written, for example, that "[p]ositivists are simply seeking an account [of law] that is properly sensitive to the different ways in which rule application and rule creation engage our theoretical and practical interests. For example, we tend to hold decision makers more responsible when they have more power to create rules; one who is merely applying rules laid down by others attracts criticism of different kinds." ${ }^{84}$ This is true as far as it goes, but that does not show that there is a single, conceptual, answer to the question that the descriptive (or conceptual) philosopher delivers to legal practitioner. In other

\footnotetext{
82 See generally Eviatar Zerubavel, The Fine Line: Making Distinctions in Everyday Life (ig9i).

${ }^{83}$ I considered the first in more detail in the past. See Priel, supra note 35; Priel, supra note 69.

${ }^{84}$ Leslie Green, The Nature of Law Today, 88 AM. POL. SCI. REV. 206, 208 (I994) (book review).
} 
words, when the question of boundary between law and nonlaw does matter (as it does in Green's example), it matters because it has political implications (and in turn occasional implications on how cases should be decided). And when that is the case, different legal systems can draw, and do draw, the boundary between law and nonlaw in different places. They do so on the basis of different views about the world, morality, politics, possibly even the state of available technology. In fact, it is even wrong to think that these boundary questions are decided differently within a given legal systems. These boundary questions are often an endless subject of disagreement and debate in a single legal system, and it is these differences in boundary-drawing that explain why people often disagree on what the law requires.

The most serious problem with this view is that even if successful, boundary questions can tell us very little if we want to understand law as a social institution. Interest in boundary questions may be of some value for setting limits to the scope or domain of the inquiry. That is, for example, how John Austin understood the preliminary enterprise he was engaged in when he sought to determine the "province" of jurisprudence. But what for him was preliminary ground-clearing (recall that The Province of Jurisprudence Determined was constituted only the first five lectures of a much broader course) became the object of conceptual jurisprudence. The problem is that if the search for boundaries is treated as the equivalent for the search for the "nature" of law, it can yield only very little information about the object of inquiry itself.

Hart, for example, argued that the move from the pre-legal to the legal requires the introduction of certain institutions (although he spoke of these institutions in terms of legal rules), of recognition, change, and adjudication. If true, this is no doubt an interesting finding; but is it true? One way of validating it would be by showing that most people actually understood law in such a way that they saw the addition of these rules as what moves us from the pre-legal to the legal world. As is well-known, there is no empirical support of this kind in The Concept of Law. Instead, Hart opted for a hermeneutic ("interpretive") approach of the intelligent observer who explains social phenomena not with empirical evidence, but by appeal to the values, ideas, and so on of the community in question (with the community in this case being the whole world). Hart explicitly endorsed this view later, ${ }^{85}$ but already in The Concept of Law Hart made his allegiance to this approach clear. In an important but neglected passage he distinguished between purely conventional labels and ones with an underlying "folk" theory:

If someone were to ask whether the placed called 'London' is really London, all we could do would be to remind him of the convention and leave him to abide by it or choose another name to suit his taste. It would be absurd, in such a case, to ask on what principle London was so called and whether this principle was acceptable. This would be absurd because, whereas the allotment of proper names rests only on an ad hoc convention, the extension of the general terms of any serious discipline is

${ }^{85}$ See HART, supra note I6, at I3-I4 (identifying his project as "hermeneutic"). 
never without its principle or rationale, though it may not be obvious what that is. When, as in the present case, the extension is queried by those who in effect say, 'We know that it is called law, but is it really law?', what is demanded — no doubt obscurely—is that the principle be made explicit and its credentials inspected. ${ }^{86}$

If applied to Hart's own account of law as the union of primary and secondary rules, the remarkable fact is that Hart did nothing in terms of identifying the underlying "principle" for the human category "law." Why is it that these three types of secondary rules are necessary for law to come to existence? Why not just two of them? Why not other types of rule in addition to the three he identified? Is this simply because only with these secondary rules do we have something that is "recognizably" legal? According to Hart himself, without explaining the "principle" underlying the classification and explaining its "credentials," we are not presented with a theory of law, an account that explains the phenomenon. Thus, even if Hart accurately described the divide between law and nonlaw, all he has given us is an empty shell, still waiting to be filled. At most we can say that Hart offered us was not a theory of law, but a research hypothesis consisting of two elements: that all humans classify law in the same way; and that they classify it in the way he suggested.

Incredibly, it is not just Hart that is silent on the matter; as far as I know, in the fifty-plus years since the publication of his book, none of Hart's followers has taken up the challenge of filling this crucial gap in his account. Focusing only on drawing the boundary lines (rather than explaining them) may help hide the fact that Hart and other immodest internalists are offering sociological accounts of law as it is found in societies with particular values. It is tempting to say that at some level such explanations were avoided because it was felt that any attempt to explain why the boundaries between law and nonlaw are drawn where they are, would have revealed that the classification is dependent on certain moral and political values. ${ }^{87}$

${ }^{86}$ HART, supra note I, at 215. This passage makes clear that Gardner's reading of Hart as an externalist is mistaken. Hart seeks the principle used by people for their classification of something as law.

${ }^{87}$ Elsewhere, I attempted to make sense of Hart's view in terms of unacknowledged political values that underlie his claims about the move from the prelegal to the legal domain. See Dan Priel, Reconstructing Fuller's Argument against Legal Positivism, 26 CAN. J.L. \& JURISPRUDENCE 399, 408-o9 (2013). While this suggestion helps make Hart's claims appear less arbitrary, the price paid is the loss of any claim to generality and descriptiveness. It might be thought that Hart could still remain descriptive and value-neutral, as long as he is merely describing those worldviews and not endorsing them. See HART, supra note I, at 244. But that will not do, because Hart was an immodest internalist, trying to derive from people's attitudes an account of the (single) institution of law is. But in any given society there are numerous people with conflicting worldviews. To say, as Hart in effect did, that a particular worldview is the one that matters for deciding what law is, goes beyond mere description. For more on the problem with describing an evaluation in this context see Priel, supra note 2, at I48-50. 


\section{B. Modest Conceptual Analysis}

Against these difficulties, it is tempting to turn to the more modest version of internalism suggested by Jackson. Though it does not seek to explain the world, it may be more revealing of people's attitudes about law. As already mentioned, many modern defenders of conceptual jurisprudence have made precisely this move. ${ }^{88}$ Even Leiter, who is otherwise a critic of conceptual jurisprudence, has conceded in some of his writings the value of this form of conceptual analysis. ${ }^{89}$ Unlike him, I believe modest conceptual jurisprudence does not fare much better than its immodest counterpart. I will identify two problems with it, first that what purports to be modest conceptual analysis often is not; and second that to the extent that it is, it is a bad form of sociology.

I. Modest conceptual jurisprudence is not really modest. The first problem with modest conceptual analysis of law is that all of its alleged instances are not modest at all. Jackson argued that conceptual analysis tells us "what the users of language mean by the words they employ." 90 This may sound unduly narrow and not particularly philosophical, but it sufficed for Jackson's purposes. Conceptual analysis for him was a preliminary step on the path to what he called "serious metaphysics," and it was required in order to delineate the subject-matter on which serious metaphysics is to be done. Not everyone accepted Jackson's views (something that legal philosophers who relied on his views have largely ignored), but even accepting them, it is notable that what purports to be modest conceptual analysis of law is not modest by Jackson's terms. I have already argued that it is difficult to see Hart's project in modest terms; the same is true of contemporary conceptualists. Ian Farrell, for example, argued that the real value of conceptual analysis is that "purport[s] to provide an underlying theory that ties together apparently disparate usages of words." As such conceptual analysis "attempts to increase our understanding of how we use words. The methodology is employed to clarify and to systematize, to make sense of the way we employ certain important terms by making explicit an underlying, inchoate, but nonetheless coherent concept or theory." ${ }^{1}$

${ }^{88}$ Farrell, supra note 73, at rooo-or; Himma, supra note 74, at 8 ("We classify things by using words, which in turn...express, mean, or convey concepts. Analysing the content of a concept, on this view, requires identifying shared practices concerning the word"); see also Veronica Rodríguez-Blanco, A Defence of Hart's Semantics as Nonambitious Conceptual Analysis, 9 LEGAL THEORY 99 (2003).

${ }^{89}$ See LEITER, supra note 6, at 196-99. Though I think the differences between us on this score are not dramatic, in my view he concedes too much. Cf. Ned Block \& Robert Stalnaker, Conceptual Analysis, Dualism, and the Explanatory Gap, I08 PHIL. REV. I, I5 (1999) ("Closing the explanatory gap in the case of life has nothing to do with any analytic definition of 'life', but rather is a matter of showing how living things around here work").

${ }^{90}$ JACKSON, supra note 23 , at 30 .

${ }^{91}$ Farrell, supra note 73, at Ioor; Himma, supra note 74, at Io, makes a similar point. 
This difference in aims for modest conceptual analysis is significant. Jackson has sought to use conceptual analysis to delineate his subject matter. That is why the examples of conceptual analysis he had in mind are, for instance, that "water is the watery stuff of our acquaintance," the kind of things that anyone familiar with the concept of water would know by virtue of familiarity with the concept, that it is liquid, transparent and so on. ${ }^{92}$ Jackson, then, at most was seeking to identify the "folk theory" of concepts like water, free action, or belief. And yet conceptual jurisprudence in its modest guise is defended for its ability to give us what is not part of the folk theory. Its value, according to Farrell, lies in its ability to increase our understanding of law, to clarify and systematize it, and so on. The examples of successful cases of conceptual jurisprudence we are presented with-law as union of primary and secondary rules, rule of recognition, exclusionary reasons-only confirm this. None of these could be said to be part of the folk theory of law. It is in fact the complexity and novelty of the ideas thought to be the products of conceptual jurisprudence that is mentioned by the proponents of conceptual jurisprudence as proof not just of the value of the enterprise, but that it is different from lexicography. ${ }^{93}$ But if true, these claims are equally telling against the suggestion that jurisprudence is an example of modest conceptual analysis. Even if one rejects the general arguments against a priori conceptual analysis, it is hard to maintain that "law is the union of primary and secondary rules" has the same status as "bachelor is an unmarried man." Thus, even if there are certain things known a priori by anyone who knows the concept of law, these are (mostly) not the things that have occupied legal philosophers in the last fifty years.

The problems with the claim that conceptual jurisprudence is modest conceptual analysis do not end here. A central rationale for engaging in conceptual analysis offered by both Hart and Farrell is that the concept of law is "principled," that despite apparent confusions it is "nonetheless coherent." But that is an unwarranted assumption. While not entirely incoherent, there is much work by cognitive psychologists that shows that our linguistic practices, that our "folk theories" of morality, politics, psychology, physics, and much else, are not perfectly principled and coherent. This is because concepts are shaped by culture, history, and evolution, not by philosophical reflection. To try to turn our conceptual jumble into a coherent theory does not look like a describing our conceptual habits, it looks like an argument for improving them.

Here is a jurisprudential example. Toward the end of The Concept of Law Hart admitted that linguistic usage on its own is consistent with both a wider ("legal positivist") understanding and a narrower ("natural law") concept of law. He then offered several arguments in favor of

\footnotetext{
92 That even this cannot be known a priori has been argued, contra Jackson, in Stephen Laurence \& Eric Margolis, Concepts and Conceptual Analysis, 67 PHil. \& Phenomenological Res. 253, 26I-63 (2003).

${ }_{93}$ See, e.g., Himma, supra note 74, at IO-II ("the lexicographer's job is accomplished in a few lines, while Hart took more than 200 pages in analysing law in The Concept of Law.")
} 
choosing the former because he thinks the positivist concept allows for better discrimination between good law, bad law, and nonlaw, whereas the natural law view collapses the last two into a single category. ${ }^{94}$ In all this Hart in effect conceded that what he took to be one of the central messages of his book - the superiority of "legal positivism" over "natural law"-is not based on the fact that it better accords with people's attitudes (as one would expect from a modest conceptualist), but rather on the fact that it should be embraced because it improves on them, or at least some of them. Hart thus argues that the positivist view provides clarity of thought absent from the natural law view. That is not a modest claim.

Related problems arise in the context of conceptual determinacy. Conceptual analysis, Farrell argues, is valuable because it "provide[s] a bridge between the clear cases and the unclear cases, [unlike] the lexicographer [who] cannot clarify whether a word can be consistently applied in situations where its usage is unclear." ${ }^{95}$ But in that case, the contribution of conceptual analysis kicks in precisely at the point where a modest conceptual project should rest. Once again, a more descriptively honest view would contend that linguistic practices are indeterminate, perhaps because we do not need them to be more precise, perhaps because we occasionally benefit from their indeterminacy.

2. If truly modest, modest conceptual jurisprudence is sociology without evidence. The other side of the coin is that to the extent that jurisprudence is truly modest, it is methodologically indefensible. It is true that conceptual analysis in this sense is not what Leiter called "glorified lexicography," but that is not the right comparator for modest internalism. Modest internalism is not glorified lexicography, it is bad sociology. On the view under consideration concepts are parts of implicit theories, and the task of conceptual analysis is to make those theories explicit. With considerable simplification we can define valuable sociological research as comprising of two components: data gathering and theorizing (explanation, in less grand terms). Modest internalism differs from sociological research not in that it is interested in "theory" whereas sociology is mere data collection. ${ }^{96}$ Both aim at theorizing, but while sociologists seek to base their claims on empirical data, legal philosophers think that introspection provides all the evidence they require.

\footnotetext{
${ }^{94}$ HART, supra note I, at 208-I2. That Hart countenances this response shows that he was not an externalist. If he had been, he would have been tempted to say, as Dickson did, that such a position involves wishful thinking. See Julie Dickson, Evaluation And Legal Theory 84-93 (200I). But if "concepts" describe human categories, there is no mystery no wishful thinking in suggesting that they be changed.

${ }^{95}$ Farrell, supra note 73, at Ioor; see also text accompanying note 9I, supra.

${ }^{96}$ Coleman appears to take the view that the sociologist merely collects data for the philosopher when he says: "Descriptive sociology enters not at the stage of providing the theory of the concept, but at the preliminary stage of providing the raw materials about which one is to theorize." Coleman, Methodology, supra note 36, at 336; see also Dickson, supra note 38 , at I39.
} 
For the sake of understanding people's attitudes about law, there is nothing wrong with relying on considered linguistic intuitions as such: they are data points on which the theory is built. After all, what the philosopher is looking for is the way people classify the(ir) social world, so testing those boundaries is the obvious way to examine the question. If a sociologist distributed a questionnaire among a representative sample of her society, presenting them with hypothetical scenarios and asking them whether they considered these scenarios to involve law, she would have asked them to report to her the same thing that a philosopher of law would have reported if presented with such a case, namely their linguistic intuitions. On the basis of the data gathered, she may then try to give an account that explains why people classify the world in the way they do (in precisely the same way that Hart talked about when he explained what the point of his inquiry was), but in doing that the inquiry goes beyond description and into an attempt at explaining social phenomena-beliefs, structures, institutions. That is precisely what sociologists try to do.

So presented, the problem with modest conceptual analysis is laid bare: it is not the reliance on intuitions that is problematic, it is the number of people whose intuitions are examined and their identity. The philosopher subjects her own concepts to several "tests," examining their borders, and argues on the basis of that what the content of certain concepts is. Himma accepted this characterization of conceptual analysis and tried to defend it in the following terms: "Armchair sociology of the sort at which philosophers excel (usually without realizing that they are doing sociology) is sufficiently reliable as long as one belongs to the linguistic community under consideration." ${ }^{" 7}$

Himma's thus accepts the argument presented here, and replies that philosophical introspection provides the requisite data for modest conceptual analysis, so long as the philosopher belongs to his linguistic community. Unfortunately, this will not do. The philosopher who thought long and hard about law is potentially unrepresentative. This is even truer in the context of jurisprudence if the philosopher in question is a trained lawyer (which is often, although not always, the case), for a lawyer's perspective of law may be unrepresentative of other members of society. Or it may not be, but we cannot know this until we have conducted a survey and compared lawyers' attitudes with those of non-lawyers. The philosopher is also quite possibly biased, because she has views she wishes to defend. This is not an idle concern: we know, after all, the different philosophers have different theoretical views about law, which (what a surprise!) correspond to their introspective intuitions about law. At the very least the existence of different intuitions among philosophers should make us wary of the suggestion that because the philosopher is a member of the "linguistic community" her linguistic

${ }^{97}$ Himma, supra note 74, at Io; see also Julie Dickson, On Naturalizing Jurisprudence: Some Comments on Brian Leiter's View of What Jurisprudence Should Become, 30 LAW \& PHIL. 477, 49I (2OII). 
intuitions are a reliable guide. The existence of different intuitions among philosophers, who are all members of the linguistic community, is enough to show that introspection is a problematic method for conducting sociological research. Presented this way, modest conceptual analysis is sociological research based on a survey with a sample of one person.

One possible response might be that the sample examined is really larger, because of the "testing" of the ideas by other philosophers who read and challenge philosophical explications of concepts. But, of course, the problems just mentioned are hardly solved when more unrepresentative philosophers are added to the mix. Moreover, the "testing" community of Anglophone jurisprudence is almost exclusively limited to legal philosophers from common law jurisdictions and as such may be unrepresentative of the attitudes of lawyers (or even legal philosophers) from other countries with different legal traditions.

This problem can be stated more generally. If we take seriously the idea that what philosophers explain are concepts, and concepts are mental entities, then it would be utterly surprising to discover that different people have the same concept of pretty much anything. As George Lakoff, a cognitive psychologist, put it, "[f]rom a neural point of view" the whole debate "makes no sense":

Concepts don't exist in some abstract philosophical universe, where they can somehow be distinguished from "conceptions" or "instantiations." Each person has a concept that makes sense to him or her. That concept is instantiated in synapses in the brain....For that person, her concept of freedom is the concept of freedom. She uses it to think with. ${ }^{98}$

When presented in this way it becomes clear, I hope, why the idea of conducting a survey with a sample of one is highly problematic. Even the somewhat more benign version, in which the sample is expanded to include the minuscule readership of jurisprudential works is extremely problematic, because the readers of works in legal philosophy make for an extremely unrepresentative (and I cannot stress this enough) sample of the general population, and one that is probably biased. Legal philosophers acknowledge the existence of "bad men," "puzzled men" and perhaps all kinds of other men (and women), but their concepts are not accorded place in this sociological account. The point Lakoff makes is that these people's concept of law is no less "genuine," true than anyone else's. It is not that they just do not understand what law really means; on this view of concepts, they just have their understanding, their concept of law. From this perspective, it makes no sense to speak of their concept as "mistaken," incomplete," or confused." It is their concept. If upon reading a work on philosophy, watching a movie,

${ }^{98}$ George Lakoff, The Political Mind: A Cognitive Scientist's Guide to Your Brain and Its POLITICS I78 (2008). It is precisely this fact that has led some philosophers to reject this psychological understanding of concepts in favor of the Platonist one. See Laurence \& Margolis, supra note 34, at 566. 
spending time in prison, or a solitary period of reflection in an Indian ashram, a person comes to change her views on what counts as law, her concept of law has changed.

Is there a way out for modest conceptual jurisprudence? Himma made another suggestion:

The idea that law has conceptually essential features...should be construed as attempting to identify those features of law that ordinary usage presupposes are essential to law. Otherwise put, the claim that such features are essential to law should be construed as conditional upon particularadmittedly contingent- practices of usage. Should those conventional practices change, the analysis of what is essential to law would also have to change. ${ }^{99}$

Such an enterprise may be valuable, "in the way it helps us understand our institutions and, through them, our culture." ${ }^{100}$ The unrelativized claims to universal necessity at least kept the façade that conceptual jurisprudence and sociology are different enterprises. Statements such as this confirm that conceptual jurisprudence is a sociological enterprise in everything but name.

I will not repeat what I said earlier about the inadequacies of conceptual jurisprudence as a way of explaining our culture. But considering this modest internalist approach helps us see why. Even relativized, intuitions provide very limited data; even necessity-relative-to-a-culture is simply too stringent a requirement for providing an illuminating discussion of culture. In addition, the relativized approach still maintains two implausible assumptions mentioned earlier, namely that the philosopher's linguistic usages are similar to "ordinary usage," and that at any given time (and place?) there is just one such usage. Lakoff's points are equally valid against this form of conceptual jurisprudence.

When so considered, the continued attachment to conceptual analysis as a mode of sociological research may appear to be an example of academic inertia, a method of inquiry that long outlived its usefulness. Conceptual analysis may be understood as a primitive and for a long time valuable form of sociological research, back when this was the only way to conducting such

${ }^{99}$ Kenneth Einar Himma, Do Philosophy and Sociology Mix? A Non-Essentialist Socio-Legal Positivist Analysis of the Concept of Law, 24 OXFORD J. LEGAL STUD. 717, 733-34 (2004) (book review). Raz likewise stated that other concepts, "similar to the concept of law, do govern the self-understanding of the basic structures and practices of political communities in...other cultures. Where they are sufficiently similar to the concept of law, or just historically continuous with it, we naturally talk of differing concepts of law. Legal theory is merely the study of the necessary features of law, given 'our' concept of law." RAZ, supra note 16, at 98. Others have suggested simply abandoning the commitment to necessity. See, e.g., Frederick Schauer, Necessity, Importance, and the Nature of Law, in NEUTRALITY, supra note 4, at I7, 24-25; Michael Giudice, Contingency and Analytical Jurisprudence, in NEW WAVES IN PHILOSOPHY OF LAW 58, 68-69 (Maksymilian Del Mar ed., 20II). So understood, however, the distinction between conceptual jurisprudence and sociology looks even more tenuous, and the inadequacy of philosophers' methods for the task they set themselves for is even more palpable.

${ }^{100}$ Leslie Green, The Concept of Law Revisited, 94 MicH. L. REV. I687, I717 (1996) (book review). This idea is derived from Raz's words quoted in text accompanying note 66, supra, but here I give it a "modest internalist" reinterpretation. Cf. Farrell, supra note 73, at Ioo2. 
studies. Socrates could not conduct adequate surveys of prevailing attitudes among his fellow Athenian citizens, so he engaged himself and his interlocutors with various hypothetical scenarios in order to gather data about their beliefs on certain issues. With considerably more charity the same might be true of Hart. Hart was a product of his time and place, and as he admitted in an interview he gave late in his life, he suffered from the "Oxford disease" of suspicion of the social sciences. ${ }^{101}$ This skeptical attitude to the social sciences may have been the product of a sense that the social sciences did not take people's internal attitudes seriously, that they were beholden of an excessively behavioristic view of science and accordingly failed to understand human nature. Around the time Hart published The Concept of Law books expressing similar views were published and they all advocated a broadly hermeneutic approach as the basis for an explanation of human action as an alternative to more naturalistic approaches to the social sciences. ${ }^{102}$

What might have been acceptable in $196 \mathrm{r}$ is simply untenable today. To continue using the introspective methodology unthinkingly more than fifty years later, despite the vast improvements made by social and cognitive scientists in explaining human behavior, at the very least calls for an argument. Interestingly, Jackson, whose work has been relied upon by various defenders of conceptual jurisprudence, explicitly stated that he sees nothing wrong with using surveys to inform "conceptual analysis" in the sense he uses the term. ${ }^{103}$ That is simply an admission that conceptual analysis in this sense is a form of sociology. As such, those who care for its supposed products should be willing to move with the times and turn to newer and better methods of data gathering. Willingness to do that, however, would have to go far beyond surveys with larger and more representative samples. It would look into the literature in cognitive and social psychology in order to get a sense of what goes on in people's heads; it would take into account the literature showing conceptual confusions and incoherence; it would consider the possible relevance of cognitive biases. Beyond that, it would seek to identify whether there are any social patterns to people's concept of law: Are there notable geographical differences to these attitudes? Are there any wealth-based, class-based, religion-based, or gender-based differences between these attitudes? Such issues are not only incapable of being

${ }^{101}$ See Hart Interviewed, supra note 15, at 289, 292 (2005) ("I was terribly mistrustful of sociology in general"); $c f$. Jack Hayward, Political Science in Britain, 20 EUR. J. POL. SCI. 30I, 30I (I99I) ("Scepticism about the possibility of political science is deeply rooted in the British intellectual tradition, represented notably by the University of Oxford").

102 See Charles Taylor, The Explanation of Behaviour (i964); A.I. Melden, Free Action (i96i); Peter Winch, The Idea of a Social Science and Its Relation to Philosophy (i958). Hart cited Winch's book in HART, supra note I, at 289, 297.

${ }^{103}$ JACKSON, supra note 23 , at 36-37. 
answered, they barely register as valid questions when debates about the concept of law are limited to a tiny group of unrepresentative individuals.

To summarize: the internalist version of conceptualism posits what might be a valuable sociological inquiry while relying on a thoroughly implausible empirical assumption (that everyone has the same concept of law) and (consequently?) countenances an unreliable methodology (introspection by the philosopher who conducts the study) as the way of gathering the relevant data for such a study. There may be considerable interest in understanding people's attitudes on law, but to find out what those are legal philosophers (after some training in social science research methods) should do a simple thing: ask people about them.

Such a view will not eliminate the need for "theorizing," it will just make theorizing more factually reliable. This view therefore is in no way tantamount to the claim that a "theoretical inquiry regarding a familiar social institution having far-reaching effects on the lives of those living under it cannot yield knowledge of that social institution itself." ${ }^{104}$ Such a conclusion is only tenable if one thinks that "knowledge of the social institution itself" is to be conducted without gathering empirical data on that social institution, or that sociologists are mere data collectors. Somewhat harshly one can say that this quote suggests a view of "theory" that is similar to that of creationists who say that evolution "is just a theory." In the sciences a theory means a body of knowledge grounded in empirical evidence that explains a phenomenon and can be used to make predictions. Against this, what legal philosophers call a "theory of law" is, charitably, only a "hypothesis." That is why I said earlier that modest internalism is descriptive sociology, badly done.

\section{Lingering Doubts}

I now wish to address four residual concerns. Two of them are, in some respects, two ways of making the same point. One is the supposed necessity of general jurisprudence, because only if we identify law in general can we talk about, say, Roman law or English law as law. The other is that in order to be able to say whether law is a good or a bad thing, we must first identify (neutrally) what law is. Both are intuitively appealing, but the conclusions drawn from them are mistaken. The other two objections, which are simpler and which I will take on first, are that conceptual analysis is just what philosophers do; and that any view that criticizes conceptual analysis is itself a form of, or depends on, conceptual analysis.

${ }^{104}$ Dickson, supra note 97 , at 489. 


\section{A. Isn't Conceptual Analysis Just What Philosophers Do?}

One encounters at times the suggestion that conceptual analysis is simply the philosopher's métier, and it is what distinguishes what they are doing, at least since Socrates and Plato, from other inquiries. ${ }^{105}$ If philosophers no longer have conceptual analysis, is there anything left for them to do? This is ultimately a question that goes to the heart of what philosophy is about, a subject deserving of (at least) a whole book. I obviously will not undertake such an inquiry here. Nevertheless, a few remarks are due.

Philosophy is a famously shrinking discipline. In the days of Aristotle all areas of learning were part of his philosophy. As late as I687, when Newton published his most famous book, he entitled it Philosophice Naturalis Principia Mathematica. The split between philosophy and psychology is more recent. In the early volumes of Mind it described itself as a "quarterly review of psychology and philosophy," the Journal of Philosophy was initially called the Journal of Philosophy, Psychology, and Scientific Method. It was not long afterwards that philosophy and psychology parted ways. Seeing their shrinking domain, philosophers may wish to cling to conceptual analysis as uniquely their own, as a methodology that defines their subject. In particular, the externalist version of conceptual jurisprudence can be understood as an attempt to carve a domain of inquiry that is, by definition, beyond the realm of empirical science. My suggestion in this essay is that in that guise much of this enterprise is indefensible; and that despite its pretensions to being some kind of unique inquiry to philosophy and a method of inquiry that delivers conceptual, pre-empirical truths, conceptual analysis is better understood as a primitive form of social inquiry. So understood conceptual analysis is not a distinct and uniquely philosophical inquiry, and just like other inquiries that used to belong to philosophy until they were displaced by science, this one is too. Conceptual analysis was a viable method of inquiry for a long time, until the development of certain mathematical and technological tools that enabled a more rigorous study of people's attitudes.

Now, if philosophy just is conceptual analysis and conceptual analysis is indefensible, the end of philosophy, including legal philosophy, follows. If that is indeed the case, it makes no sense to go on with a hopeless enterprise just for the sake of continuity with the past. But the conclusion seems premature, because the premise that philosophy equals conceptual analysis is false. Without making any attempt to define the proper role of philosophy, all I can offer here are some observations. Much of what gets published nowadays in philosophy journals is not conceptual analysis; indeed, in this regard, the suggestion that there is no room for jurisprudence without conceptual analysis is not a way of affirming jurisprudence's standing

105 See Coleman, supra note 67, at 175; Coleman, Methodology, supra note 36, at 343; Oberdiek \& Patterson, supra note 8 , at $63-64$. 
alongside other branches of philosophy, it highlights how out of step it is. One need not just look to areas like philosophy of science or mind, where philosophers these days are engaged much more with the actual results of science, rather than perceiving themselves as providing Eternal Truths for scientists to work with. Even the closer domain of political philosophy is instructive. John Rawls's success in turning what was a moribund area of philosophy, one that only a decade earlier had been declared dead, to one of the most vibrant fields in contemporary philosophy is at least in part attributable to the fact that $A$ Theory of Justice was not an exercise in conceptual analysis. Rather than seeking to maintain political philosophy by identifying the "proper" domain of philosophy as the one to which other disciplines cannot intrude, rather than trying to explicate the concept of justice, Rawls has shown by example that political philosophy is best done by engaging with the works of economists, political scientists, even psychologists and linguists. It may be that a similar shift would not work equally well in the philosophy of law (or it may be that much work of this kind is already being done, except that it is not called "philosophy of law"); but there is not yet need to despair.

\section{B. The Inescapability of Conceptual Analysis}

There are two versions of the argument from the inescapability of conceptual analysis. One is that the critique of conceptual jurisprudence is itself an example of conceptual analysis, and is therefore self-defeating. The second version is that any supposedly non-conceptual version of jurisprudence is (necessarily) committed to conceptual analysis.

Given the structure of my arguments in this essay, I have an easy response to the first argument, and it is that my arguments did not challenge conceptual analysis in general, only conceptual analysis as applied to law. Therefore, I can remain agnostic on the broader debates in philosophy about conceptual analysis. It may be that there is a valid conceptual inquiry about the nature of bachelorhood, perhaps even about the nature of social constructions in general. It does not follow that there is a valid conceptual inquiry about the nature of law. To admit that conceptual analysis is necessary for an argument about the right way to investigate law does not imply that the investigation of law itself requires conceptual analysis. If it turns out that this essay engaged in conceptual analysis, so be it. Nevertheless, despite this easy response, I would not want to leave the matter at that. It is difficult to prove a negative, but as far as I can see, none of the arguments I presented here involved conceptual analysis, and therefore I believe the first challenge is mistaken.

The second argument does not claim the challenge to conceptual jurisprudence is itself conceptual; it asserts that supposedly non-conceptual forms of jurisprudence depend on conceptual analysis. This argument received a clear statement in Jules Coleman's response to Leiter's call for naturalistic jurisprudence: "there is no reason to think that... a social-scientific 
project can be a substitute for the philosophical methodology of analytic jurisprudence. In fact the naturalized project can proceed only after a good deal of philosophical spadework has been done." 106 Coleman illustrates this claim with an example: "The very idea of an adjudicatory function operating on authoritative legal standards presupposes that we have criteria for determining what the authoritative legal standards are. Thus, the naturalist is committed as a conceptual matter to the existence of a test of legality." 107

This argument is correct as far as it goes, but its implications are fairly modest. Granted, social scientific research makes assumptions of about what law is, and it is perfectly valid (and, as I have tried to show in this essay, important) to bring those assumptions to light. As Daniel Dennett (a naturalistic philosopher if there ever was one) once said: "there is no such thing as philosophy-free science; there is only science whose philosophical baggage is taken on board without examination." ${ }^{108}$ The examination of the assumptions of scientific studies involves bringing to light the way one's variables are defined and the way this may skew one's conclusions. Though this kind of work is extensively conducted by scientists themselves, philosophers can participate in it, and may even have an advantage in it. As outsiders to the scientific community they may be able to notice the assumptions that scientists take for granted.

One might think that such an inquiry can only be done against a background of knowing what law "really" is: How can the philosopher criticize the assumptions of the social scientist as mistaken unless she knows what law is? But that conclusion is mistaken. The social scientist may (and will) say that her assumptions and definitions were chosen for their ease of conducting the study, because they conform with prevailing attitudes in the general population, and for other possible reasons. Of course, not any choice will do: implausible assumptions may lead to useless findings ("garbage in, garbage out," as they say). It does not follow from that, that social scientists need to know the true nature of law, even if such a thing exists. The fact that social scientists do not wait for legal philosophers to resolve their disputes strongly suggests that they do not think they need to wait for the philosophers' disputes to end. The fact that they succeed in delivering useful, testable findings shows that they are not wrong to do so. If social scientific findings are illuminating, predictive, and so on, that is all the social scientist needs to vindicate her inquiry. In short, the fact that social scientists inevitably make assumptions in their studies, justifies examining those assumptions; it does not vindicate conceptual jurisprudence as a preliminary study without which social science is impossible.

\footnotetext{
${ }^{106}$ COLEMAN, supra note 105, at 213; see also Oberdiek \& Patterson, supra note 105, at 75.

${ }^{107}$ COLEMAN, supra note IO5, at 2I3-I4.

108 Daniel C. DennetT, DARWIN's Dangerous Idea: Evolution AND the MEANings OF LifE 2i (I995).
} 


\section{Does Description Necessarily Come before Evaluation?}

A related worry, this time directed at legal philosophers who reject the view that jurisprudence is descriptive, is that there is some logical priority to understanding what something is before going on to evaluate it. Those theorists who claim that answers to the question "what is law?" are evaluative are thus either confused or (more likely) silently presupposing an answer to what law is.

It is not difficult to find examples of such a view. Gardner has argued that the question "what is law?" is "logically prior" to the question "what is good law?"109 In similar fashion, Dickson stated that

[i]n asking whether we ought to obey the law, we are asking we ought to obey a particular sort of social institution which differs from other forms of social organization in that it operates via certain distinctive procedure and institutional means. We need to know, therefore what those procedures and means are in order to have the information relevant to trying to answer whether law ought to be obeyed. ${ }^{110}$

In a slightly different context but along similar lines, Green has stated that "sociologists are trying to develop empirical measures of the rule of law. To know whether these are valid measures of their target, we need to know what the rule of law is."111

There is no denying the intuitive appeal of this view; it is this appeal that explains why some legal philosophers find those philosophers who reject it (notably Ronald Dworkin) so obviously wrong. Despite its apparent obviousness, I think it is mistaken. Explaining why in detail will require a separate article, but we encountered already the key to the answer. There is no pretheoretical agreement on what counts as law or the rule of law, and there is no noncircular, "conceptual" way of deciding who is right. By contrast, if one combines some loose, even conflicting, pretheoretical ideas about the practice with a normative idea (typically about what the practice is for), one can escape the circularity and derive from one's normative assumptions a more clearly articulated view of what the practice "is." This is an unabashedly non-descriptive inquiry, one in which the "ought" (what the practice is for) blends in, and perhaps precedes, the "is." Such an inquiry is evaluated largely (although not exclusively) by the

${ }^{109}$ See John Gardner, Legal Positivism: 51/2 Myths, 46 AM. J. JuRIS. 199, 226 (200I). Gardner, I should say, has later retracted this claim. See GARDNER, supra note Io, at I67 n.28. But elsewhere in same book Gardner says something that sounds very much like yet another endorsement of the logical priority claim: "one must already know what counts as law before one can make either empirical or evaluative observations about it qua law." Id. at 275-76.

${ }^{110}$ DiCKSON, supra note 94, at I35; see also id. at $\mathrm{I}_{3} 6$ ("[ $\left.\mathrm{t}\right]$ here are...many prior questions which we need to ask and attempt to answer before we can even get to the point where we can formulate, let alone answer, the directly evaluative questions about the law which we might eventually wish to."); $c f$. Giudice, supra note 99, at 63.

${ }^{111}$ Leslie Green, Introduction to HART, supra note I, at xv, xlvi; $c f$. Green, supra note Ioo, at I687 (general jurisprudence aims, among other things, "to promote serious moral assessment of [legal] institutions"). 
force of its normative implications. This is, of course, the barest outline of the approach Dworkin called “interpretivism." Although Dworkin's view has been denounced by many legal philosophers, I believe it is practiced far more widely than it is believed. I will simply assert here with no argument that I believe many of Dworkin's critics (for example, Hart, Raz, and Dickson, to name but a few) are unacknowledged practitioners of interpretivism, and whatever value people may have found in their work on law is because they provided interesting interpretations of certain contemporary law.

\section{Does Special Jurisprudence Presuppose General Jurisprudence?}

In the course of his defense of general jurisprudence Gardner writes:

If there is nothing to be said about law in general, then there is also nothing to be said about particular instances of law qua law. If law is not a valid classification, then nor is Cheyenne law, international law, Scots law, shari'a law, or Roman law. If there is no general jurisprudence...then there is also no special jurisprudence. ${ }^{112}$

If true, Gardner would have shown the necessity of conceptual jurisprudence. Unfortunately, none of his claims is persuasive. Let me start at the end, because the last sentence is clearly false. Even if one rejects the possibility or significance of a search for the nature of law in general, it is a mistake to think there is no special jurisprudence, i.e. the most general account of the philosophy of (say) English law. I will first offer an explanation that I am not sympathetic with, but which anyone who accepts the view that there is such a thing as general jurisprudence describing the nature of law, must accept. General jurisprudence on this view is the essence of all legal systems. It logically follows that the essence of the English legal system includes all that and more. It is those things that English law shares with all other legal system that makes it English law (that is "general jurisprudence"), it is the additional essential features that make it English law (that is "special jurisprudence" of English law). So the special jurisprudence of English law on this view is general jurisprudence plus more. Anyone who believes in the viability of the search for the nature of law, should see no difficulty in the search for the nature of English law.

Here, for those unsatisfied, is a philosophical thought experiment. Imagine someone who only knows of English law. Can that person not write a book about the philosophy of English law? There is no reason to think that she cannot. Now imagine that that person learns of a new legal system: does that invalidate her account of the nature of English law? I cannot see why it would: by definition our scholar sought to give an account of the nature of the law she knew,

\footnotetext{
${ }^{112}$ GARDNER, supra note Io, at 279. This seems to me also to be the point in Dickson, supra note 37, at 68-69; MOORE, supra note I, at 8I ("If we want to compare institutions such as law or religion in different cultures, we will have to have some idea of what law or religions are”).
} 
which happened to be English law. How could the discovery that Spanish law existed have any relevance for that? If one recognizes this, the same is true even if we know that there are other legal systems out there before we start our investigation of the nature of a particular legal system. Suppose our scholar now examines Spanish law and discovers that it does not have anything in common with English law. Would that undermine his conclusions about the nature of English law? Again, it is not clear why. Indeed, she could then go on to produce a study of the nature of Spanish law alongside his earlier study of the nature of English law even though there is no more general account.

Perhaps Gardner would deny that the nature of English law is the nature of law plus other things: the nature of English law is just the nature of law as instantiated in England. In other words, there is no such thing as the nature of English law, there are only different instantiations of law in different places. This explains why Gardner says that if there is no general jurisprudence "there is also nothing to be said about particular instances of law qua law." Gardner suggests here that it would make no sense to speak of Roman law as if it is a species of a genus, law, and yet we clearly do that. So understood, the claim that special jurisprudence presupposes general jurisprudence assumes that what makes social practices belong to a single genus is their identical properties. It is for this reason that Gardner stated that "[i]f law is not a valid classification, then nor is Cheyenne law, international law, Scots law, shari'a law, or Roman law." To put the point a bit more conspicuously, if we do not assume that English law and Roman law belong to the same genus, it makes as much sense to pair them together as it does to pair English law with Roman furniture.

Rather than vindicating the search for the nature of law, this argument simply repeats the circularity that lies at its core. To begin, what evidence does Gardner have that Roman law and English law as two species of one genus apart from linguistic usage? None, as far as I can tell. But linguistic usage is capacious enough to use words that do not share a nature. Gardner does not think that Roman law, the laws of nature, and Murphy's Law, share a nature. If we discount linguistic usage, then there is no basis for assuming that English and Roman law share a nature. Furthermore, as I briefly indicated earlier, there is at least one alternative account which allows for this possibility. It is one that I happen to think is superficially far more plausible than the one assumed by Gardner, and which his arguments do not rule out. This is the view about the historical transformation of law through the ages, coupled with a corresponding historical story as to why the term used to describe this changing practice has remained constant. Whatever unity there might exist between English and Roman law will not be the product of them having the same essential features; it will be arrived at by showing how they both depend on a complex network of ideas, some elements of which they share, albeit in different ways. To know this will require investigating the inner workings of English and Roman law, precisely the kind empirical 
or historical inquiry that Gardner's vision of legal philosophy is supposed to be different from. And such an inquiry will recognize special jurisprudence of English law and Roman law, may even recognize a sense in which it makes sense to use the same word ("law") to describe both, while at the same time denying that there is any general jurisprudence that finds the feature that both has "qua law."

\section{If Not Conceptual Jurisprudence, What then?}

If we take a step back from the details, we can see within the jurisprudential terrain a recapitulation of broader philosophical positions. Externalists of various forms are rationalists, who believe that with the power of pure reason they can make valuable discoveries about what certain features of the world are like. Juxtaposing the jurisprudential externalists against philosophical rationalists, however, helps us see how extreme their position is. Rationalists these days argue that we can know that reason alone can teach us that $7+5=12$, that nothing can be red and green all over at the same time, and so on. ${ }^{113}$ Their jurisprudential counterparts go much beyond. They tell us that the existence conditions of the human institution of law are independent of human creation (which is why all humans can get them wrong), and that they can be discovered by philosophical reflection on imaginary scenarios.

The internalists are jurisprudence's empiricists. They suggest a kind of empirical inquiry to learn what the law is. The methods of the legal philosophers are supposed to tell what people think law is. Immodest conceptual analysis, the kind that was practiced by Hart stands in the middle between these positions. (It may be that for this reason that proponents of both modest internalism and externalism could see themselves as followers of Hart's methods.) This middle position is reflective of the philosophical aspirations of its early proponents. By examining human language and the way it created a world, philosophers believed they could transcend the rationalist-empiricist divide. Human language created a world of meanings, which were the building blocks of the entire social world around us. Attention to language could thus yield genuine answers to what the world was like without having to assume that intuitions gave humans access to a world of Platonic forms.

The internalist variant emerges as the more plausible one. Human language and thought are immensely important for understanding the complex reality that makes up the social world. The major flaw with this approach to jurisprudence is that, possibly out of some resistance to the applicability of the methods of science to investigating human affairs, its proponents think of

113 See, e.g., Laurence BonJour, In Defense of Pure Reason: A Rationalist Account of A Priori JUSTIFICATION (I998). 
philosophical methods as a superior alternative to a well-designed empirical study of these questions, rather than as a more primitive form of it.

Either way, if I am right, the conclusion seems to be that a dominant strand of contemporary analytic jurisprudence requires serious rethinking. If my arguments are successful, do they spell the end of jurisprudence? That depends on what one means by jurisprudence. If what one means by this is the conceptual, descriptive, supposedly pre-sociological debates that dominated Anglophone jurisprudence in the last sixty-or-so years, then I think the inevitable answer is "Yes." Conceptual jurisprudence should be abandoned, not because (as some have suggested) it is an uninteresting enterprise, but because it is a fundamentally misguided one.

Why should we think that this is what jurisprudence must be? To give just two examples, the much-maligned work of Lon Fuller and Ronald Dworkin emerges from this article largely unscathed. Because of the dominance of conceptual jurisprudence it has often been assumed that they engaged (only badly) in conceptual jurisprudence; actually, both are better understood as early critics of conceptual jurisprudence. ${ }^{114}$ Whatever gripes one may have with their views, their general approach is not challenged by anything I said here.

Beyond the familiar figures of contemporary jurisprudence, one can read this essay as a call for reviving pre-Hartian jurisprudence. Those who defend Hart now credit him for "transform[ing] the discipline": "What had been a dilettantish pastime for law teachers and retired judges, an undisciplined jumble of history, speculative sociology, legal doctrine and party politics, became technical and rigorous branch of philosophy." ${ }^{115}$ There is a different take on these words: From an inquiry into law in general, which was understandably unconfined by disciplinary boundaries, but borrowed freely from history, sociology, legal doctrine, politics, as well as philosophy, jurisprudence has become more-or-less synonymous with legal philosophy. Even within philosophy, it was only a narrow segment that counted as legal philosophy proper. A revived pre-Hartian jurisprudence would reject this inhibiting constraint, and even more vehemently the idea that jurisprudence should be focused on the search for the nature, essence, concept, or necessary features of law.

It may be that by the standards of contemporary scholarship some of the pre-Hartian work now appears "dilettantish," but that is true of much of the scholarship of that time, regardless of discipline. "Professional" philosophy being largely a twentieth-century invention, it is not just much work in jurisprudence that by today's standards may look amateurish. The same is true of many of the great classics of philosophy (just as much as it is of the classics of other disciplines).

\footnotetext{
${ }^{114}$ In relation to Fuller see Dan Priel, Fuller's Political Jurisprudence of Freedom, io JERUSALEM REV. LEGAL STUD. 18, 4I-44 (20I4).

${ }^{115}$ Leslie J. Green \& Brian Leiter, Letter to the Editor, H.L.A. Hart and 'The Concept of Law', TIMES LITERARY SuPP., March II, 2005, at I5, I5. Similar remarks are found in MOORE, supra note I, at 64.
} 
It is therefore probably general changes in academic standards, that brought about these changes to jurisprudence, changes to which Hart's work may well have been an effect more than a cause. Be that as it may, adopting Hart's "professionalism" does not require us to adopt his disciplinary strictures. Quite the contrary; these days philosophers working in other areas care a great deal about works in other disciplines. Many philosophers of mind look to work in cognitive science and psychology, philosophers of science know more than a little bit of the scientific questions they are writing on, there is work in political philosophy that makes use of empirical, "positive" political theory or on the history of political thought. Against this, the isolationist attitude of legal philosophers with regard to not just to the contributions of other disciplines to the study of law, but with regard to legal practice and the attitudes of its practitioners, is the one that stands out as outdated and by today's academic standards, unprofessional. By contrast, that old "jumble" of information and ideas coming from various disciplines looks to be more in tune with our times.

More than anything else, it is hard to square the alleged "professionalism" of contemporary jurisprudence with the almost theological reverence accorded to The Concept of Law, both as an arbiter of what kind of questions properly belong to the domain jurisprudence and as a guideline to the right approach to investigating them. There is, quite simply, no book in any other of branch of philosophy that comes close to dominating the field in this way. Consequently, an approach that can hardly be said to be older than Hart's book has come to be seen as defining what jurisprudence "is about" to such an extent that works that do not fit it are ruled not to belong to the field. ${ }^{116}$ Explaining how one could revive jurisprudence will take more than an essay. A good first step would be to stop the unprofessional practice of reading with veneration, and perhaps reading at all, the book most responsible for the misguided conceptualist orientation that dominates contemporary jurisprudence.

${ }^{116}$ See, e.g., MARMOR, supra note I, at 32 (concluding from the fact that the legal realists were not interested in the question "what is law?" that "the realists were not interested in the philosophy of law"); MoORE, supra note I, at I99 ("much of [Robert] Summers's sociological work leaves the impression of being an answer to a question that is not asked by any properly focused legal theory"); GARDNER, supra note Io, at I84 ("Dworkin had different concerns that only overlapped to a limited extent with Hart's. Dworkin was and remains much more of a lawyer than Hart."). In an earlier version of this essay Gardner was even more explicit, calling Dworkin a "theoretically ambitious lawyer" (as opposed to a legal philosopher), as "he had different concerns that only overlapped to a limited extent with Hart's." John Gardner, The Legality of Law, I7 RATIO JURIS I68, I73 (2004). 